Max-Planck-Institut für demografische Forschung

Max Planck Institute for Demographic Research

Konrad-Zuse-Strasse 1 - D-18057 Rostock = Germany = Tel +49 (0) 3812081 - 0 - Fax +49 (0) 3812081 - 202 - www.demogr.mpg.de

MPIDR Working Paper WP 2019-010 I June 2019

The Effect of Widowhood on

Mortality in Polygamous Marriages:

Evidence from the

Utah Population Database

Kieron Barclay I barclay@demogr.mpg.de

Robyn Donrovich Thorén

Heidi Hanson

Ken R. Smith

(C) Copyright is held by the authors.

Working papers of the Max Planck Institute for Demographic Research receive only limited review. Views or opinions expressed in working papers are attributable to the authors and do not necessarily reflect those of the Institute. 


\title{
THE EFFECT OF WIDOWHOOD ON MORTALITY IN POLYGAMOUS MARRIAGES: EVIDENCE FROM THE UTAH POPULATION DATABASE
}

\author{
KIERON BARCLAY ${ }^{1,2,3}$, ROBYN DONROVICH THORÉN, HEIDI HANSON ${ }^{4,5}$ AND KEN R. SMITH ${ }^{4,6}$
}

AbSTRACT. Although the increase in mortality following widowhood has been widely studied, much less is known about how this pattern varies across less common household structures. Polygamous marriages are still prevalent across much of the world, but whether and how mortality varies following the death of a partner has not been studied in polygamous relationships. In this study we use data from the Utah Population Database to examine the relationship between marital status and mortality in polygamous marriages in 19th century Utah. With data on 110,952 women and 106,898 men, we particularly focus on whether the widowhood mortality effect varies between monogamous and polygamous marriages. We examine how the number of wife deaths affects male mortality in polygamous marriages, how the death of a sister wife, meaning other women with whom they share a husband, affects female mortality relative to the death of a husband, as well as how marriage order amongst sister wives affects the mortality of women in polygamous marriages. For women we find that the death of a husband in polygamous marriages increases mortality to a similar extent as in monogamous marriages, while the death of a sister wife does not have a qualitatively different effect on mortality than the death of the husband. Marriage order does not play a role in the mortality of women in polygamous marriages in this historical context. For men we find that the death of one wife in a polygamous marriage increases mortality to a lesser extent than it does for men in monogamous marriages. For men there is a dose-response effect to losing additional wives. We discuss these findings in relation to theories regarding the mechanisms driving the widowhood mortality effect.

\footnotetext{
${ }^{1}$ Max Planck Institute for Demographic Research

${ }^{2}$ Department of Social Policy, London School of Economics and Political Science

${ }^{3}$ Department of Sociology, Stockholm University

${ }^{4}$ Population Sciences, Huntsman Cancer Institute

${ }^{5}$ Department of Surgery, University of Utah

${ }^{6}$ Department of Family and Consumer Studies, University of Utah
} 


\section{INTRODUCTION}

The detrimental effect of losing a spouse on the mortality of the surviving partner is one of the most consistently observed patterns in the social sciences (Hu and Goldman, 1990; Martikainen and Valkonen, 1996; Smith and Zick, 1996; Mineau et al., 2002; Elwert and Christakis, 2008a). Although practically all individuals will experience some form of bereavement over the life course, the loss of a spouse is an extremely stressful event and can induce depression, feelings of anxiety, guilt, and hopelessness (Stroebe et al., 2007), as well as related behavioural changes. A meta-analysis of 123 previous studies has shown that the widowhood effect is typically worse for men than it is for women, with men experiencing an increase in mortality rates of around 27\%, and women experiencing an increase of around 15\% (Shor et al., 2012). These main effects, however, suppress substantial effect heterogeneity. Studies have shown that the widowhood effect is moderated by a variety of factors including age, time since widowhood, geographical region, historical period (Smith and Zick, 1996; Shor et al., 2012), and race (Elwert and Christakis, 2006). To date, however, research has focused upon the widowhood effect in monogamous marriages. Although monogamous marriages are today the most common type of marriages, $80 \%$ of preindustrial societies permitted polygamy, most commonly in the form of polygyny (Murdock and White, 1969). Furthermore, polygyny is legal or tolerated across much

of sub-Saharan Africa and the Middle East today (Bledsoe, 1990; Jacoby, 1995; Al-Krenawi, 2014; Smith-Greenaway and Trinitapoli, 2014).

In this study we extend research on the widowhood mortality effect by examining the effect of losing a spouse in polygamous marriages in historical Utah. During the 19th century the Church of Jesus Christ of Latter-day Saints endorsed the practice of polygamy (Gordon, 2002). Using the Utah Population Database, a remarkable data source with individual-level information and kinship linkages from the 17th century to the present day, we examine whether the widowhood mortality effect differed in polygamous marriages relative to monogamous marriages. Furthermore we are also able to examine whether there were differential effects, for women, of losing a husband or a sister wife, meaning other women with whom they share a husband, and for 
men, of the death of more than one wife. As a result we are able to examine the extent to which there are dose-response patterns in the widowhood mortality effect. Another aim of this study is to shed light on the different mechanisms by which the widowhood mortality effect has been hypothesized to operate. In particular, examining the relative effect for women of the death of a sister wife versus the death of a husband may reveal whether the widowhood mortality effect is attributable to shared environmental exposures, or a direct consequence of spousal loss. Studying the widowhood mortality effect in polygamous marriages provides an opportunity to test these mechanisms in a way that would otherwise not be possible. We further examine whether patterns of mortality differ by marriage order for wives in polygamous marriages independent of the effects of husband death, and how marriage order interacts with widowhood.

The Effect of Widowhood on Mortality in Historical Contexts. Although the vast majority of research on the widowhood mortality effect has been based on data from the second half of the twentieth century, several studies have also addressed this pattern in a historical context (e.g. see Campbell and Lee, 1996; Van Poppel and Joung, 2001; Nystedt, 2002; Mineau et al., 2002; Alter et al., 2007). A meta-analysis of previous research has shown that the increase in mortality associated with losing a spouse has increased gradually over previous decades, but was also evident in historical periods (Shor et al., 2012). Indeed, in historical contexts where resources could be scarce, the death of a spouse could have serious consequences. Using data from Northeast China over the period 1774-1873, Campbell and Lee (1996) found that the death of a spouse was associated with a very substantial increase in the odds of mortality in the next three years, and that the negative effect of spousal death was worse for women than it was for men. Using historical data from Sweden, Belgium and the Netherlands, Alter et al. (2007) found that widowhood increased the mortality of women, and the death of a spouse was particularly detrimental when a woman had multiple children and lost her husband at a young age. Nystedt (2002) found that men suffered more than women from the death of a spouse using historical data from the Skåne region in Sweden. 
A study using the Utah Population Database to examine four different marriage cohorts over the period 1860-1989 found a negative effect of spousal death on the survival rates of men across all four cohorts, and particularly when they had lost a spouse at a young age (Mineau et al., 2002). However, Mineau et al. (2002) found that women did not consistently suffer from the widowhood mortality effect. Previous research on marital status and mortality using the Utah Population Database has not considered how mortality patterns might differ amongst those in polygamous relationships. Polygynous marriage, a kinship system where men marry multiple wives, was practiced by some members of the Church of Jesus Christ of Latter-day Saints in 19th century Utah. Data from the Utah Population Database indicate that the frequency of polygamous men as a fraction of all married men was highest amongst men born in 1833, at $17.8 \%$ (Smith and Kunz, 1976; Moorad et al., 2011). Decennial censuses showed that the proportion of the population in polygamous families reach a peak around 1860, when $43.6 \%$ men, women, and children were in a polygamous family of some sort, though this proportion is heavily dominated by children (Bushman, 2008). After this peak the proportion declined over time, until the equivalent figure was $25 \%$ in 1880, and 7.1\% in 1900 (Bushman, 2008). New strictures on the practice of polygyny began with the Morrill Anti-Bigamy Act of 1862 which outlawed plural marriage throughout the US territories. The US Supreme Court upheld the ban in the face of a freedom of religion challenge in 1878 and, in 1890, the Mormon Church issued the Woodruff Manifesto which officially banned polygyny as a condition of achieving statehood for Utah.

Explanations for the Effect of Widowhood on Mortality. While the widowhood mortality effect has been observed consistently across time and a wide variety of contexts, this pattern of results could be produced by a number of different mechanisms. Most studies suggest that the increase in the mortality of the surviving spouse is indeed a direct consequence of the death of the partner. Although there is evidence for gender and race heterogeneity in the survival benefits derived from marriage (Elwert and Christakis, 2006), studies have consistently shown that those who are married have better physical and mental health (Hu and Goldman, 1990; Drefahl, 
2012). While positive selection into marriage explains part of this advantage (Mastekaasa, 1992; Murray, 2000; Stutzer and Frey, 2006), there are also clear reasons why marriage should be beneficial for both partners. A growing body of research has demonstrated the importance of social networks and social support for health and well-being (House et al., 1988; Smith and Christakis, 2008), and for most individuals the relationship with a spouse is amongst the most intimate that they experience. Being married connects individuals to a larger social network, but more importantly partners provide social and emotional support, financial support, and monitor one another's health and health behaviours. Studies have shown that men in particular are more likely to eat more healthily, and to drink less alcohol, when they are married (Umberson, 1987; Umberson et al., 1992), though both men and women exercise less when they are married in contemporary settings (Nomaguchi and Bianchi, 2004). Women often have more dependable sources of social support outside of marriage than men, and are therefore less reliant on their partner for support (Antonucci and Akiyama, 1987). Some research indicates that the benefits of marriage for women are typically derived primarily from the financial benefits of marriage (Lillard and Waite, 1995). This may be particularly true in a historical context where a traditional gender division of labor in marriage was dominant.

The death of a spouse typically induces acute emotional distress for the surviving partner (Stroebe et al., 2007). Studies have shown that widowed men and women are more likely to adopt less healthy behaviours, eating less well, consuming more alcohol, and smoking more, but that this reaction is typically more pronounced for men (Umberson, 1992). Poor health behaviours are particularly likely in the period directly after spousal loss, and this is especially pronounced for men as wives play a critical role in maintaining male health (Jin and Chrisatakis, 2009). A considerable part of the widowhood mortality effect seems to be attributable to reliance on the partner, and some research suggests that individuals in marriages where the couples have a less pronounced division of labour are less negatively affected by widowhood as they are more self-sufficient (Elwert and Christakis, 2006). Although widowed individuals 
almost always have worse health than married individuals, those who are widowed may maintain better health than those who were never married, even after taking selection processes into account; the benefits of marriage can persist even after partner death because the preceding years have shaped patterns of health behaviours that are not immediately unlearned (Elwert and Christakis, 2006), and the benefits of marriage are cumulative (Umberson et al., 2006). Greater health and better habits are also likely to increase the probability that an individual might remarry following widowhood (Mineau et al., 2002). Therefore, after adjusting for age, those who are remarried may even be healthier than those who are married but never widowed as they are a select group and also benefit from the positive benefits associated with marriage.

While previous research shows that the increase in mortality risk after losing a partner is widespread, the evidence for effect heterogeneity by various sociodemographic characteristics (Elwert and Christakis, 2006; Shor et al., 2012), suggests that there may also be effect heterogeneity by marriage type, particularly when marriage type is also related to socioeconomic status. In the 19th century the territory that would later become the State of Utah in 1896 was a frontier society where settlers had to contend with a harsh physical environment (Bean et al., 1990). Food supplies were uncertain due to the risk of crop failure and because of the relative geographic isolation (Arrington and May, 1975; Hanson and Smith, 2013). Furthermore, medical knowledge and facilities were limited (Mineau et al., 2002). In such an environment, men who could afford to marry multiple women typically had greater financial resources, which studies have shown may mitigate risks in times of scarcity (Lawson et al., 2015). On this basis, we would expect that men in polygamous marriages would have lower mortality than men in monogamous marriages, primarily as a result of selection based upon socioeconomic resources and status within the Church of Jesus Christ of Latter-day Saints. Furthermore, in polygynous marriages, if a wife died, this would mean that the surviving husband would not completely lose his access to emotional support, or the support from remaining wives in raising children. Previous studies have shown that the presence of kin, including children (O'Bryant, 1988; Mineau et al., 2002), is an important factor mitigating the negative consequences of widowhood, and the 
presence of an additional spouse would be likely to play a similar role. Likewise for widowed women in plural marriages, losing either a husband or a sister wife would mean that they would still have access to social support from other household members. However, to the extent that previous research has shown that the health benefits of marriage primarily extend from access to financial resources from the husband (Lillard and Waite, 1995), the death of a husband in a plural marriage would be expected to have a greater impact on the surviving woman than the death of a sister wife. Men and women in polygynous marriages would also be expected to have lower mortality by virtue of their membership of the Church of Jesus Christ of Latter-day Saints, and the associated tenets that forbade the consumption of alcohol or tobacco (Bush, 1993).

Another factor that might play an important role in the survival of women in polygamous marriages is marriage order (Jankowiak et al., 2005; Bove and Valeggia, 2009). Most of the empirical literature examining the relationship between marriage order and wife outcomes is based upon studies of polygynous households in Africa, but there are also some studies based upon Mormon households. Studies generally indicate that first and earlier ranked wives have higher fertility than later wives (Bean and Mineau, 1986; Gibson and Mace, 2007), and that the children of first wives are more likely to attend school (Mammen, 2009), have better nutrition (Gibson and Mace, 2007), and have lower mortality (Strassmann, 1997). First wives also spend a period of time with the husband in a monogamous marriage before later wives join (Josephson, 2002). To the extent that exclusive access to resources from the husband affects health, this would benefit the health of the first wife and her children. Furthermore, a longer tenure within the household may give the first wife greater status and control over the allocation of resources within the household (Mulder, 1989). If any such authority or status rank exists though, it is hard to predict how that would evolve following the death of the husband. Although it may be inappropriate to generalise from such a different context, research using data from rural Ethiopia has shown that first wives tend to be younger and have a higher bride price than later wives, suggesting that later wives are considered to have a lower value (Gibson and Mace, 2007). In 19th century Utah, second and later wives also tended to be older than the first wife 
at the time of marriage (Josephson, 2002), though they are almost always younger than the first wife at the time that they join the marriage. This previous research tentatively suggests that after taking age into account, higher marriage order may be associated with a higher risk of mortality. However, it may be that later wives attract the particular favour of the husband, which may lead to relative survival advantages within the family.

Potential Sources of Bias. Given that many careful studies have found a widowhood mortality effect on the mortality of the surviving spouse, the overall consensus is that there is a causal effect of widowhood on mortality and that the observed pattern is not due to statistical confounding (Shor et al., 2012). Nevertheless, a widowhood mortality effect could be produced by at least two different sorts of bias, related to homophily, and shared environmental exposures (Smith and Zick, 1994; Elwert and Christakis, 2008b). A wealth of studies have demonstrated the pattern of positive assortativity in the formation of social relationships (McPherson et al., 2001). Individuals who share one or more traits are more likely to form social, including romantic, relationships. Studies indicate that partners in romantic relationships tend to be similar on a variety of different factors, including educational levels, health, and health behaviours. If spouses select into a relationship based on similar health, or health behaviours, the widowhood mortality effect on mortality might be the product of homophily bias (Goldman, 1993; Smith and Zick, 1994). A study by Elwert and Christakis (2008b) attempted to address the potential of homophily bias by comparing how the death of an ex-wife and the death of a current wife affect the mortality of husbands. Positive assortative mating is likely to occur in both first marriages as well as second marriages, so the health and health behaviours of a husband are likely to be correlated with both the health and health behaviours of the first and the second wife. If homophily bias was an important factor producing the widowhood mortality effect, then the death of an ex-wife would be expected to increase the mortality of a husband. However, Elwert and Christakis (2008b) found that the death of an ex-wife did not increase the mortality of the husband, while the death of a current wife did. Although that study does not completely rule out the potential for homophily bias, and there are likely to be different selection processes related 
to who marries a second wife, and which women are willing to marry a divorced man, it does offer persuasive evidence that homophily bias is not the key driver of the observed widowhood mortality effect.

A second source of potential bias that might be producing the widowhood mortality effect is the importance of shared environment. Environmental factors can play an important role in mortality. Husbands and wives typically live together, meaning that if there is some kind of factor in the environment that increases the risk of mortality, such as arsenic in the groundwater (Lewis et al., 1999) which is a common problem in the Southwestern United States (Welch et al., 1988), then both partners will be exposed to that risk. This common exposure to risk could also produce a correlation in the timing of death between a husband and wife. No study to date has been able to distinguish the relative importance of a genuine bereavement effect from a shared environment effect in producing the widowhood mortality effect. In this study we intend to examine whether, for women, the death of a sister wife influences mortality in a way that is different from the loss of a husband. If a shared environment exposure is responsible for producing the widowhood mortality effect, then we would expect that the death of a sister wife and the death of the husband would have a similar effect on the mortality of the surviving wife. However, if the death of the husband has a significantly greater effect on the mortality of the surviving wife than the death of a sister wife, then that would provide persuasive evidence for the importance of a genuine bereavement effect over a spurious pattern that is a product of a shared environment. Likewise, for polygynous men we would expect that the death of any wife should lead to a substantial increase in mortality if it is attributable to a shared environmental exposure. However, if the widowhood mortality effect is attributable to the loss of social support, the presence of remaining surviving wives should diminish the negative effects of widowhood, and the relative effect of the death of a wife should be lower for a man in a polygynous marriage than for a man in a monogamous marriage. However, we should see that the mortality of men in polygamous marriages should be substantially elevated in the case that all of his wives are deceased. 


\section{DATA AND METHODS}

Data. This study is based on data from the Utah Population Database (UPDB). The central component of UPDB is an extensive set of Utah family histories, in which family members are linked to demographic and medical information. The UPDB contains information on more than eleven million individuals, including the genealogies of the founders of Utah and their Utah descendants, sourced from the Genealogical Society of Utah. The genealogy records for early migrants, their families, and their descendants represent birth cohorts that date back to the period around 1760. These early records provided basic demographic information on almost 200,000 families (more than 1.6 million individuals). These early records have been linked across generations, and in some instances the records encompass as many as eleven generations. Individuals in these data may or may not have an affiliation to the Church of Jesus Christ of Latter-day Saints and may have lived in other states or countries. The genealogy records have been linked to other data sets, including Utah birth and death certificates, cancer records, the Social Security Death Index, and the 1880 Utah Territorial Census. Multiple sources of death information are available in UPDB for parents and their children, including genealogy records, Utah death certificates beginning in 1904, and the Social Security Death Index. The analysis for this study is limited to individuals born up to 1900. We follow individuals from the point at which they marry until the time of death. Divorce was less common in 19th century Utah, so marriage most commonly ended with the death of the spouse, or one's own death.

Marital Status. Our key explanatory variable is marital status, which we treat as a time-varying covariate. This is important, as we distinguish between monogamous and polygamous marriages in our analyses, and a monogamous marriage does not become polygamous until at least a second woman joins that marriage. Furthermore, it is critical to model widowhood, the death of more than one wife, the death of a sister wife, and remarriage after widowhood using a timevarying approach. As a result, the relative risks estimated in our event history analyses reflect the hazard of mortality of an individual in a given marital state, and the same individual may 
contribute exposure to multiple different categories of our marital status variables (e.g. married, widowed, remarried). We conduct separate analyses for men and women. Our main analyses for men are for those who had up to four wives, but we also conduct supplementary analyses to include the minority of men who had more than four wives. The sample size for the analytical population for women is 110,952 , and for men is 106,898 .

Our analyses for women include women who had up to three husbands, which is explained by remarriage following the death of the partner, but only a tiny fraction of women had more than two husbands since this required the death of two husbands as well as a second remarriage. As a result, we collapse first and second monogamous remarriages, and second and third husband deaths in monogamous marriages, into the same categories. We model not only the death of husbands, but also the deaths of sister wives. The categories for marital status that we use for our analyses of women are as follows:

(1) First monogamous marriage

(2) Widowed in first monogamous marriage

(3) Remarried (second or third monogamous marriage)

(4) Widowed again (second or third monogamous marriage)

(5) Polygamous marriage where the husband and all sister wives are alive

(6) Polygamous marriage where the husband is alive, and some of the sister wives have died

(7) Polygamous marriage where the husband is alive and all sister wives are dead

(8) Polygamous marriage where the husband is dead but all sister wives are alive

(9) Polygamous marriage where the husband is dead, and some of the sister wives are dead

(10) Polygamous marriage where the husband and all of the sister wives are dead

Since very few women have more than one polygamous husband, which would require being widowed in the first polygamous marriage and then remarrying into another polygamous marriage, we collapse all higher order polygamous marriages into the same categories. For example, if a women joins a polygamous marriage, and is then widowed, and then remarried into a second polygamous marriage, she could move from state (5) above to state (8), and back to 
state (5) again in the second marriage. We have conducted analyses where we model second and third marriages as completely separate states, but the patterns were qualitatively similar across first, second, and third marriages, so we collapsed the categories together in order to increase precision. We also run analyses with a simplified set of categories for polygamous marriages (states 5 to 7 below) to reduce some of the inherent complexity encountered when codifying various marriage states that include plural unions:

(1) First monogamous marriage

(2) Widowed in first monogamous marriage

(3) Remarried (second or third monogamous marriage)

(4) Widowed again (second or third monogamous marriage)

(5) Polygamous marriage where all sister wives and the husband are alive

(6) Polygamous marriage where some, but not all, of the marriage group are deceased

(7) Polygamous marriage where all members of the marriage group are deceased.

In these analyses of women we also control for several variables that refer to the husband (e.g. socioeconomic status of the husband), or the wife-husband dynamic (e.g. age difference between wife and husband). If a woman is widowed, she retains the values for these variables from the deceased husband until the time at which she might remarry, at which point those variables are updated to reflect the characteristics of the new husband.

Amongst women we also study the relationship between marriage order and mortality. We study marriage order effects in first marriages that were polygamous. We conduct separate analyses by the size of the marriage group $(2, \ldots, 5+)$. In these analyses we condition on all preceding sister wives being alive at the time that the index person joins the marriage. We introduce this condition because higher order wives might be 'replacements' for previously deceased wives in polygamous marriages, and this produces a statistical artifact whereby earlier wives have a relative mortality risk much greater than higher order wives.

Our analyses for men include a marital status variable with eighteen categories: 
(1) First monogamous marriage

(2) Widowed from first monogamous marriage

(3) First monogamous remarriage

(4) Widowed from second monogamous marriage

(5) Second monogamous remarriage

(6) Widowed from third monogamous remarriage

(7) Polygamous marriage with two wives, where both wives are alive

(8) Polygamous marriage with two wives, where one wife has died

(9) Polygamous marriage with two wives, where both wives are deceased

(10) Polygamous marriage with three wives, where all wives are alive

(11) Polygamous marriage with three wives, where one wife has died

(12) Polygamous marriage with three wives, where two wives have died

(13) Polygamous marriage with three wives, where all three wives are deceased

(14) Polygamous marriage with four wives, where all wives are alive

(15) Polygamous marriage with four wives, where one wife has died

(16) Polygamous marriage with four wives, where two wives have died

(17) Polygamous marriage with four wives, where three wives have died

(18) Polygamous marriage with four wives, where all four wives are deceased

As mentioned above, an index individual may move between these different states, and may contribute exposure to each state that he occupies in the event history analysis. For example, a man in a monogamous marriage who then takes a second wife will move from state (1) to state (7), and if he then takes on a third wife, and none of the wives have died, he will move to state (10). If he outlived all three of his wives, he would then move from state (10) through states (11), (12), and (13).

Covariates. In our analyses of women, we control for birth cohort, membership of the Church of Jesus Christ of Latter-day Saints, whether the woman was born outside of Utah or not, biological parity, age difference from the husband (husband age minus wife age), the occupational 
status of the husband, and whether the husband was a farmer. The variable for parity is timevarying. In our analyses of men we control for birth cohort, membership of the Church of Jesus Christ of Latter-day Saints, whether the man was born outside of Utah or not, biological parity, the occupational status of the man, and whether the man was a farmer. The variable for biological parity is also time-varying for men. A number of studies in both contemporary and historical populations show that parity is related to health and mortality (Umberson et al., 1992; Friedlander, 1996; Smith et al., 2002; Hurt et al., 2006), and men with more wives are also likely to have more children. Polygamous men whose wives die generally will have many children and rearing these children would be a stressor. We include this time-varying covariate as a categorical variable with values $1,2, \ldots, 10,11-14,15-19$, and $20+$. We also stratify our analyses by age at first marriage for both men and women, to take account of how that would influence patterns of mortality amongst the ever married.

Birth cohort is a categorical variable that groups together those who are born in the 1700s, who are few, and ten-year groupings for those born from 1800 to 1900 . Our measure for the socioeconomic status of the husband is a NPSES (Nam-Powers-Boyd) occupational status score for a measure of occupational status (Nam and Boyd, 2004). NPSES is a measure of occupational status based on the median earnings and educational attainment associated with each category in the occupational scheme. It is the percentage of persons in the labor force with occupations having combined levels of education and earnings below that level, and so scores range from 0 to 99 . We include this variable in the models split into 11 categories $(1-9,10-19, \ldots, 90-99$, and missing). We also include a separate dummy variable to indicate whether they were farmers or not, as this was a very common occupation in the study period. It is important to adjust for husband SES as having a high SES is associated with a lower risk of mortality, and high socioeconomic status men were generally able to attract more wives. We control for the SES of the husband in both our analyses of men and of women because women in this era typically did not participate in the labor market, and household socioeconomic status is best determined by the husband's occupational status. 
We adjust for membership of the Church of Jesus Christ of Latter-day Saints as it is directly linked to the likelihood of entering a plural marriage in the first place, and also related to mortality risk. Due to behavioral norms codified in the Word of Wisdom, members of the Church of Jesus Christ of Latter-day Saints have a proscription from alcohol and tobacco use and the emphasis placed on community and social integration, as well as monthly fasting, means that health outcomes for both the men and women in our sample are related to membership of the Church of Jesus Christ of Latter-day Saints. This variable has three categories: 1) non-member; 2) inactive member; and, 3) active member. Active members of the Church of Jesus Christ of Latter-day Saints are those who have pledged to abide by the doctrine of the Church of Jesus Christ of Latter-day Saints. We consider individuals that have made this pledge to be active members of the Church of Jesus Christ of Latter-day Saints. Inactive members are those who were baptized as children but where we have no evidence that they later pledged to abide by the Church doctrine. We control for age difference between the husband and wife as research suggests that the age difference between partners affects their hazard of mortality (Drefahl, 2010). We recode this variable for the difference between the husband's minus the wife's age into seven categories: $<-9 ;-9$ to $-5 ;-4$ to $-1 ;-1$ to $1 ; 1$ to $4 ; 5$ to $9 ;>9$. We do not control for this in our analyses of men because there is no single value for age difference between husband and wife for men who have multiple wives. We prefer to omit the covariate for spousal age difference rather than to assume the mean age difference across multiple wives.

Statistical Analyses. To study the relationship between marital status and mortality we use survival analysis in the form of Cox proportional hazard models (Cox, 1972). The general proportional hazards model is expressed as:

$$
h\left(t \mid X_{1}, \ldots, X_{k}\right)=h_{0}(t) \exp \left(\sum_{j=1}^{k} \beta_{j} X_{j}(t)\right)
$$

where $h\left(t \mid X_{1}, \ldots, X_{k}\right)$ is the hazard rate for individuals with characteristics $X_{1}, \ldots, X_{k}$ at time $t$, $h_{0}(t)$ is the baseline hazard at time $t$, and $\beta_{j}, j=1, \ldots, k$ are the estimated coefficients. The 
failure event in our analysis is the death of the index person, and the baseline hazard in our model $h_{0}(t)$ is time since first marriage. We censor on the time when the person is lost to follow-up or outmigration from Utah, which is recorded in the UPDB.

We also estimate a series of stratified Cox models, which allows us to stratify the baseline hazard by different groups, based upon the assumption that there are unobserved factors particular to each category that may lower or elevate the shared hazard. This allows us to effectively adjust for factors that are shared within strata to the extent that they are time-invariant (Allison, 2009). The stratified Cox model takes the following form, where the hazard for an individual from stratum $s$ is:

$$
\mathrm{h}_{s}\left(t \mid X_{1}, \ldots, X_{k}\right)=h_{0 s}(t) \exp \left(\sum_{j=1}^{k} \beta_{j} X_{j}(t)\right)
$$

where $h_{0 s}(t)$ is the baseline hazard for stratum $s, s=1, \ldots, S$. Our general strategy is to stratify by age at first marriage in single-year age groups, since the baseline hazard in our models is time since first marriage. This effectively allows us to adjust for age differences in mortality. We also employ stratified Cox models in order to examine the effect of marriage order on the mortality of women in polygamous marriages; in these models we stratify by the shared husband ID. Nested within each husband the wives share the same baseline hazard, which adjusts for factors that are shared by wives to the extent that they are time-invariant (Allison, 2009). In the models where we stratify by shared husband ID, we explicitly control for age at first marriage using individual-age dummy variables (i.e. $16,17, \ldots, 59,60+$ ). In our models stratifying by shared husband ID we also estimate cluster-adjusted robust standard errors clustered at the level of the shared husband ID (Lin and Wei, 1989).

In the following section we present the results from several models. The models that we estimate for women are as follows: Model 1, using a Cox model stratified by age at first marriage, adjusts for birth cohort and membership of the Church of Jesus Christ of Latter-day Saints. Model 2, also using a Cox model stratified by age at first marriage, introduces additional covariates for whether the woman was born outside of Utah or not, the occupational status of 
the husband, whether the husband was a farmer, age difference from the husband, and a timevarying covariate for biological parity. We estimate these two models for both our detailed and simplified marital status variables. In our analyses addressing mortality effects of marriage order of women in polygynous marriages, we stratify by husband and control for age at first marriage as well as birth year in addition to the full suite of covariates from Model 2.

In our analyses of men, Model 1 is a Cox model stratified by age at first marriage, and adjusts for birth cohort and membership of the Church of Jesus Christ of Latter-day Saints. Model 2, also applies a Cox model stratified by age at first marriage, and introduces additional covariates for whether the man was born outside of Utah or not, the occupational status of the man, whether the man was a farmer, and a time-varying covariate for biological parity.

\section{RESUlts}

Descriptives. Tables 1 and 2 show descriptive statistics for the analytical sample that we use in our analyses. Table 1 shows the descriptive statistics for the analyses based upon women by whether the marriage was monogamous or polygamous. These unconditional rates show that women in polygamous marriages where all of the husbands and sister wives were alive had similar, but slightly lower, mortality than women in monogamous marriages who had not been widowed. The unconditional rates show that mortality in polygamous marriages was progressively higher as sister wives died, then higher still when the husband died, and even higher when both the husband and sister wives died. These unconditional rates indicate that the death of a husband is more consequential than the death of a sister wife, but the death of both the husband and sister wives is associated with the highest mortality rates for the index woman. Amongst women in monogamous marriages, the death of a husband is associated with a very substantial increase in mortality. Women who remarried a second or third time have a lower unconditional mortality rate than those who are widowed, but higher than those who were never widowed. Women in monogamous marriages who were widowed again in the second or third marriage have the highest unconditional mortality rate of all women in monogamous marriages. 
TABLE 1. Descriptive Statistics for Analytical Population: Women

\begin{tabular}{|c|c|c|c|c|c|c|c|}
\hline & & \multicolumn{3}{|c|}{ Monogamous } & \multicolumn{3}{|c|}{ Polygamous } \\
\hline & & Person-years (\%) & Deaths & Rate $\left(10^{-2}\right)$ & Person-years (\%) & Deaths & Rate $\left(10^{-2}\right)$ \\
\hline \multirow[t]{10}{*}{ Marital Status } & Monogamous, first marriage & 72.13 & 39,703 & 1.02 & & & \\
\hline & Monogamous, first widowhood & 20.57 & 58,768 & 5.30 & & & \\
\hline & Monogamous, remarried & 1.43 & 931 & 1.21 & & & \\
\hline & Monogamous, widowed again & 0.67 & 2,254 & 6.23 & & & \\
\hline & Polygamous, husband and all sister wives alive & & & & 3.10 & 1,624 & 0.97 \\
\hline & Polygamous, husband alive, some sister wives dead & & & & 0.41 & 323 & 1.48 \\
\hline & Polygamous, husband alive, all sister wives dead & & & & 0.25 & 283 & 2.11 \\
\hline & Polygamous, husband dead, all sister wives alive & & & & 0.64 & 1,196 & 3.47 \\
\hline & Polygamous, husband dead, some sister wives dead & & & & 0.43 & 1,249 & 5.35 \\
\hline & Polygamous, husband and all sister wives dead & & & & 0.37 & 1,574 & 7.88 \\
\hline \multirow[t]{11}{*}{ Birth cohort } & $<1800$ & 0.57 & 659 & 2.16 & 0.01 & 19 & 4.92 \\
\hline & 1800-1809 & 0.79 & 891 & 2.10 & 0.04 & 74 & 3.78 \\
\hline & 1810-1819 & 1.35 & 1,558 & 2.14 & 0.19 & 305 & 2.97 \\
\hline & $1820-1829$ & 2.07 & 2,390 & 2.14 & 0.52 & 702 & 2.49 \\
\hline & $1830-1839$ & 2.92 & 3,299 & 2.09 & 1.16 & 1,365 & 2.19 \\
\hline & $1840-1849$ & 4.28 & 4,719 & 2.05 & 1.21 & 1,449 & 2.22 \\
\hline & $1850-1859$ & 7.62 & 8,399 & 2.05 & 1.16 & 1,308 & 2.10 \\
\hline & $1860-1869$ & 11.75 & 12,980 & 2.05 & 0.71 & 788 & 2.07 \\
\hline & $1870-1879$ & 16.00 & 17,622 & 2.04 & 0.13 & 162 & 2.23 \\
\hline & $1880-1889$ & 20.81 & 22,303 & 1.99 & 0.07 & 69 & 1.87 \\
\hline & $1890-1900$ & 26.65 & 26,836 & 1.87 & 0.01 & 8 & 1.54 \\
\hline Membership of Church & Non-member & 15.32 & 14,342 & 1.74 & 0.41 & 490 & 2.21 \\
\hline of Jesus Christ & Inactive & 20.16 & 13,592 & 1.25 & 0.28 & 269 & 1.78 \\
\hline of Latter-day Saints & Active & 59.32 & 73,722 & 2.31 & 4.51 & 5,490 & 2.26 \\
\hline Age difference between & $<-9$ & 13.55 & 14,944 & 2.05 & 2.86 & 3,167 & 2.06 \\
\hline \multirow{6}{*}{ wife and husband } & -9 to -5 & 27.65 & 29,189 & 1.96 & 1.12 & 1,369 & 2.28 \\
\hline & -4 to -1 & 29.81 & 31,299 & 1.95 & 0.67 & 899 & 2.49 \\
\hline & -1 to 1 & 18.40 & 19,770 & 1.99 & 0.37 & 529 & 2.62 \\
\hline & 1 to 4 & 4.00 & 4,645 & 2.16 & 0.11 & 167 & 2.78 \\
\hline & 5 to 9 & 1.14 & 1,470 & 2.38 & 0.06 & 89 & 2.99 \\
\hline & $>9$ & 0.18 & 272 & 2.74 & 0.01 & 29 & 3.59 \\
\hline \multirow[t]{11}{*}{ Biological parity } & 0 & 9.13 & 7,954 & 1.62 & 0.29 & 253 & 1.64 \\
\hline & 1 & 9.28 & 7,066 & 1.41 & 0.24 & 168 & 1.28 \\
\hline & 2 & 10.16 & 8,349 & 1.52 & 0.29 & 223 & 1.41 \\
\hline & 3 & 10.47 & 9,406 & 1.67 & 0.33 & 287 & 1.60 \\
\hline & 4 & 10.19 & 10,142 & 1.85 & 0.37 & 349 & 1.74 \\
\hline & 5 & 9.19 & 9,784 & 1.98 & 0.45 & 466 & 1.94 \\
\hline & 6 & 8.19 & 9,445 & 2.14 & 0.47 & 540 & 2.12 \\
\hline & 7 & 7.00 & 8,650 & 2.29 & 0.49 & 594 & 2.25 \\
\hline & 8 & 5.93 & 7,799 & 2.44 & 0.49 & 658 & 2.47 \\
\hline & 9 & 4.98 & 6,996 & 2.61 & 0.50 & 692 & 2.57 \\
\hline & $10+$ & 10.28 & 16,065 & 2.90 & 1.27 & 2,019 & 2.95 \\
\hline \multirow[t]{2}{*}{ Born outside of Utah } & No & 59.38 & 62,866 & 1.97 & 1.17 & 1,311 & 2.07 \\
\hline & Yes & 35.42 & 38,790 & 2.03 & 4.03 & 4,938 & 2.28 \\
\hline Husband Nam-Powers & 1 (Low) & 0.56 & 595 & 1.99 & 0.00 & 5 & 2.92 \\
\hline \multirow{10}{*}{ score } & 2 & 1.51 & 1,629 & 2.01 & 0.05 & 63 & 2.13 \\
\hline & 3 & 5.13 & 5,554 & 2.01 & 0.08 & 94 & 2.13 \\
\hline & 4 & 2.28 & 2,458 & 2.00 & 0.07 & 86 & 2.19 \\
\hline & 5 & 30.02 & 32,290 & 2.00 & 1.34 & 1,592 & 2.21 \\
\hline & 6 & 4.93 & 5,207 & 1.96 & 0.09 & 105 & 2.28 \\
\hline & 7 & 3.97 & 4,103 & 1.92 & 0.15 & 177 & 2.22 \\
\hline & 8 & 5.87 & 6,050 & 1.91 & 0.10 & 121 & 2.17 \\
\hline & 9 & 3.26 & 3,336 & 1.90 & 0.06 & 69 & 2.10 \\
\hline & 10 (High) & 2.28 & 2,313 & 1.89 & 0.07 & 88 & 2.33 \\
\hline & Missing & 34.99 & 38,119 & 2.02 & 3.18 & 3,849 & 2.24 \\
\hline \multirow{2}{*}{ Husband farmer } & No & 70.19 & 75,117 & 1.99 & 4.03 & 4,850 & 2.23 \\
\hline & Yes & 24.61 & 26,537 & 2.00 & 1.17 & 1,399 & 2.21 \\
\hline \multirow[t]{10}{*}{ Age at first marriage } & $10-19$ & 33.58 & 34,545 & 1.91 & 2.72 & 3,096 & 2.11 \\
\hline & $20-24$ & 44.10 & 46,539 & 1.96 & 1.67 & 2,033 & 2.25 \\
\hline & $25-29$ & 12.20 & 13,836 & 2.11 & 0.51 & 679 & 2.46 \\
\hline & $30-34$ & 3.07 & 3,836 & 2.32 & 0.19 & 262 & 2.54 \\
\hline & $35-39$ & 1.05 & 1,447 & 2.55 & 0.07 & 104 & 2.94 \\
\hline & $40-44$ & 0.39 & 587 & 2.82 & 0.02 & 39 & 3.47 \\
\hline & $45-49$ & 0.20 & 352 & 3.28 & 0.01 & 18 & 4.61 \\
\hline & $50-54$ & 0.09 & 180 & 3.76 & 0.00 & 10 & 4.09 \\
\hline & $55-59$ & 0.06 & 132 & 4.25 & 0.00 & 4 & 3.57 \\
\hline & $60+$ & 0.07 & 202 & 5.75 & 0.00 & 4 & 17.45 \\
\hline
\end{tabular}


TABLE 2. Descriptive Statistics for Analytical Population: Men

\begin{tabular}{|c|c|c|c|c|c|c|c|}
\hline & & \multicolumn{3}{|c|}{ Monogamous } & \multicolumn{3}{|c|}{ Polygamous } \\
\hline & & Person-years (\%) & Deaths & Rate $\left(10^{-2}\right)$ & Person-years (\%) & Deaths & Rate $\left(10^{-2}\right)$ \\
\hline \multirow[t]{18}{*}{ Marital status } & Monogamous, first marriage & 85.39 & 66,394 & 1.68 & & & \\
\hline & Monogamous, first widowhood & 8.21 & 27,218 & 7.14 & & & \\
\hline & Monogamous, second marriage & 4.14 & 5,532 & 2.88 & & & \\
\hline & Monogamous, second widowhood & 0.34 & 1,399 & 8.95 & & & \\
\hline & Monogamous, third marriage & 0.18 & 308 & 3.73 & & & \\
\hline & Monogamous, third widowhood & 0.02 & 96 & 9.74 & & & \\
\hline & Polygamous, two wives, both alive & & & & 0.97 & 656 & 1.45 \\
\hline & Polygamous, two wives, one dead & & & & 0.25 & 530 & 4.48 \\
\hline & Polygamous, two wives, both dead & & & & 0.04 & 193 & 10.91 \\
\hline & Polygamous, three wives, all alive & & & & 0.17 & 135 & 1.75 \\
\hline & Polygamous, three wives, one dead & & & & 0.14 & 222 & 3.33 \\
\hline & Polygamous, three wives, two dead & & & & 0.05 & 143 & 5.95 \\
\hline & Polygamous, three wives, all dead & & & & 0.00 & 27 & 13.83 \\
\hline & Polygamous, four wives, all alive & & & & 0.03 & 28 & 1.89 \\
\hline & Polygamous, four wives, one dead & & & & 0.04 & 45 & 2.69 \\
\hline & Polygamous, four wives, two dead & & & & 0.02 & 36 & 4.88 \\
\hline & Polygamous, four wives, three dead & & & & 0.01 & 26 & 7.21 \\
\hline & Polygamous, four wives, all dead & & & & 0.00 & 10 & 22.57 \\
\hline \multirow[t]{11}{*}{ Birth cohort } & $<1800$ & 0.59 & 638 & 2.34 & 0.00 & 8 & 6.12 \\
\hline & $1800-1809$ & 0.68 & 744 & 2.36 & 0.03 & 53 & 3.51 \\
\hline & $1810-1819$ & 1.23 & 1,287 & 2.26 & 0.13 & 187 & 3.09 \\
\hline & $1820-1829$ & 2.02 & 2,112 & 2.25 & 0.33 & 403 & 2.63 \\
\hline & $1830-1839$ & 3.08 & 3,101 & 2.17 & 0.44 & 525 & 2.58 \\
\hline & $1840-1849$ & 4.66 & 4,804 & 2.22 & 0.39 & 448 & 2.48 \\
\hline & $1850-1859$ & 8.70 & 8,884 & 2.20 & 0.30 & 316 & 2.28 \\
\hline & $1860-1869$ & 12.87 & 13,405 & 2.24 & 0.07 & 85 & 2.45 \\
\hline & $1870-1879$ & 16.87 & 17,848 & 2.28 & 0.02 & 24 & 2.22 \\
\hline & $1880-1889$ & 21.96 & 22,741 & 2.23 & 0.00 & 2 & 2.04 \\
\hline & $1890-1900$ & 25.62 & 25,383 & 2.13 & & & \\
\hline \multirow{17}{*}{$\begin{array}{l}\text { Membership of Church } \\
\text { of Jesus Christ } \\
\text { of Latter-day Saints } \\
\text { Biological parity }\end{array}$} & Non-member & 19.21 & 18,523 & 2.08 & 0.05 & 50 & 2.27 \\
\hline & Inactive & 20.05 & 16,477 & 1.77 & 0.04 & 36 & 2.03 \\
\hline & Active & 59.01 & 65,947 & 2.41 & 1.64 & 1,965 & 2.58 \\
\hline & 0 & 10.30 & 8,116 & 1.70 & 0.00 & 2 & 0.94 \\
\hline & 1 & 10.47 & 7,578 & 1.56 & 0.01 & 1 & 0.29 \\
\hline & 2 & 11.13 & 8,754 & 1.69 & 0.01 & 1 & 0.15 \\
\hline & 3 & 11.24 & 9,845 & 1.89 & 0.02 & 2 & 0.20 \\
\hline & 4 & 10.55 & 10,115 & 2.06 & 0.03 & 11 & 0.72 \\
\hline & 5 & 9.36 & 9,713 & 2.24 & 0.04 & 19 & 0.91 \\
\hline & 6 & 8.05 & 9,014 & 2.41 & 0.05 & 14 & 0.64 \\
\hline & 7 & 6.81 & 8,135 & 2.57 & 0.06 & 28 & 1.00 \\
\hline & 8 & 5.63 & 7,214 & 2.76 & 0.07 & 35 & 1.16 \\
\hline & 9 & 4.61 & 6,360 & 2.98 & 0.08 & 56 & 1.53 \\
\hline & 10 & 3.54 & 5,209 & 3.17 & 0.09 & 83 & 1.89 \\
\hline & $11-14$ & 5.98 & 9,685 & 3.49 & 0.40 & 407 & 2.21 \\
\hline & $15-19$ & 0.57 & 1,106 & 4.22 & 0.49 & 681 & 2.98 \\
\hline & $20+$ & 0.04 & 103 & 5.03 & 0.36 & 711 & 4.22 \\
\hline \multirow[t]{2}{*}{ Born outside of Utah } & No & 61.73 & 63,043 & 2.20 & 0.26 & 280 & 2.31 \\
\hline & Yes & 36.55 & 37,904 & 2.23 & 1.46 & 1,771 & 2.61 \\
\hline Nam-Powers & 1 (Low) & 0.59 & 675 & 2.46 & 0.00 & 2 & 4.16 \\
\hline \multirow[t]{10}{*}{ occupational score } & 2 & 1.67 & 1,638 & 2.12 & 0.02 & 24 & 2.20 \\
\hline & 3 & 5.17 & 5,876 & 2.45 & 0.03 & 33 & 2.25 \\
\hline & 4 & 2.56 & 2,577 & 2.17 & 0.03 & 29 & 2.23 \\
\hline & 5 & 32.18 & 31,700 & 2.12 & 0.59 & 596 & 2.17 \\
\hline & 6 & 5.26 & 5,677 & 2.32 & 0.04 & 39 & 2.24 \\
\hline & 7 & 4.34 & 4,331 & 2.15 & 0.06 & 65 & 2.28 \\
\hline & 8 & 6.52 & 6,418 & 2.12 & 0.04 & 40 & 2.12 \\
\hline & 9 & 3.67 & 3,521 & 2.07 & 0.02 & 23 & 2.20 \\
\hline & 10 (High) & 2.37 & 2,341 & 2.13 & 0.02 & 26 & 2.47 \\
\hline & Missing & 33.94 & 36,193 & 2.30 & 0.86 & 1,174 & 2.93 \\
\hline \multirow[t]{2}{*}{ Farmer } & No & 72.11 & 75,351 & 2.25 & 1.20 & 1,521 & 2.74 \\
\hline & Yes & 26.17 & 25,596 & 2.11 & 0.53 & 530 & 2.17 \\
\hline \multirow{10}{*}{ Age at first marriage } & $10-19$ & 5.16 & 4,832 & 2.02 & 0.18 & 207 & 2.51 \\
\hline & $20-24$ & 48.21 & 46,539 & 2.08 & 1.05 & 1,203 & 2.47 \\
\hline & $25-29$ & 30.73 & 31,723 & 2.22 & 0.37 & 460 & 2.65 \\
\hline & $30-34$ & 9.25 & 10,566 & 2.46 & 0.09 & 129 & 2.96 \\
\hline & $35-39$ & 2.91 & 3,806 & 2.82 & 0.02 & 27 & 3.31 \\
\hline & $40-44$ & 1.10 & 1,645 & 3.22 & 0.01 & 10 & 3.21 \\
\hline & $45-49$ & 0.48 & 802 & 3.62 & 0.01 & 11 & 4.02 \\
\hline & $50-54$ & 0.24 & 471 & 4.14 & 0.00 & 2 & 5.16 \\
\hline & $55-59$ & 0.11 & 263 & 5.02 & 0.00 & 1 & 8.37 \\
\hline & $60+$ & 0.09 & 300 & 7.49 & 0.00 & 1 & 79.06 \\
\hline
\end{tabular}


Table 2 shows the descriptive statistics for the analyses based upon men. Men in polygamous marriages with two wives where neither wife has died have the lowest unconditional mortality rates, followed by men with four or more wives where none have died, men in a monogamous marriage where the wife is alive, and men with three wives where none have died. Amongst men in polygamous marriages, it is clear that the unconditional mortality rate increase monotonically as the proportion of wives who died out of the total number of wives increases. However, we see that when all wives are dead, mortality is highest amongst men who had four or more wives in comparison to men who had three wives or two wives. Men in polygamous marriages who have lost all of their wives have higher unconditional mortality rates than men in monogamous marriages who have been widowed. Amongst men in monogamous marriages, being widowed is associated with a higher unconditional rate of mortality, while remarrying is associated with a rate of mortality higher than men who have not been widowed, but lower than those who had not remarried. Thus, men who have remarried twice but were widowed three times have the highest unconditional rates of mortality amongst all men in monogamous marriages. The high percentage of men missing information on occupational status can be attributed to a lack of links to death certificates or the census in these cases, or a death outside of Utah.

\section{Multivariate Regressions.}

Women. The results from the multivariate analyses examining the relationship between marital status and mortality amongst women can be seen in Figure 1. Please note that the estimates shown in the left and right panel are from the same model, where the common reference category is women in monogamous relationships who have not been widowed; the split into separate panels is purely to assist interpretation of the results. A detailed table of results including covariates can be found in Table S1 in the Supplementary Information. The results from model 1 are based upon an analysis adjusting for birth cohort and membership of the Church of Jesus

Christ of Latter-day Saints, and stratifying by age at first marriage. Compared to non-widowed women in monogamous marriages, widowed women who had been living in a monogamous 

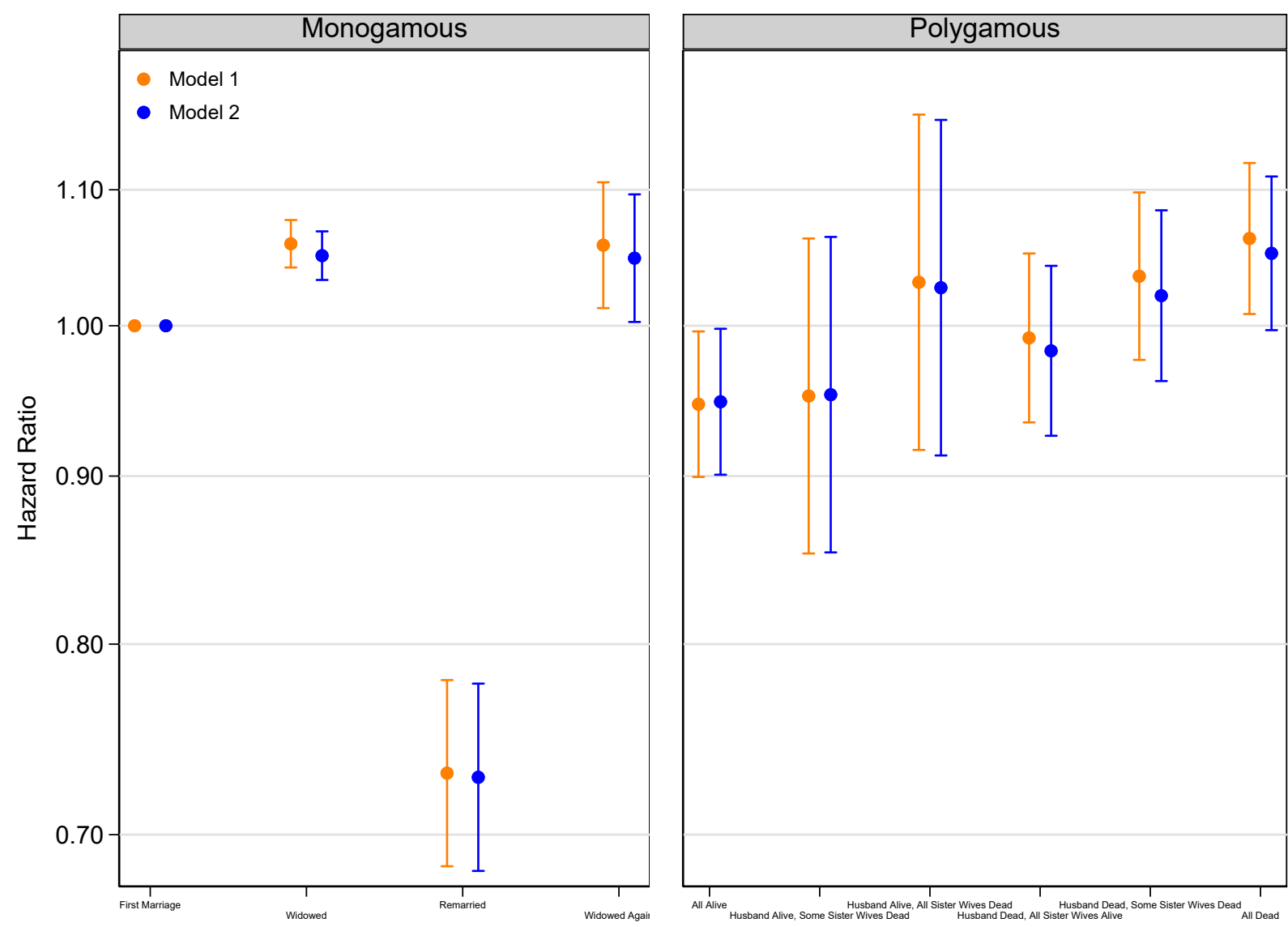

FIGURE 1. Detailed marital status of women and mortality. Error bars are $95 \%$ confidence intervals. Note that the estimates shown in the left and right panel are from the same model, where the common reference category is women in first monogamous marriages who have not been widowed.

marriage have mortality that is $8 \%$ higher. Women in monogamous marriages who remarry have substantially lower mortality than women who were never widowed, with a hazard ratio of 0.73. Women who were widowed again following remarriage have a hazard of mortality very similar to women widowed from the first monogamous marriage. Remarkably, the results from models 1 and 2 are very similar, indicating that the there is very little confounding or mediating from the socioeconomic characteristics of the husband or from fertility behaviour.

Women in polygamous marriages have significantly lower mortality than women in monogamous marriages, and even when women in polygamous marriages experience the death of their husband and their sister wives, their relative risk of mortality is not statistically significantly 
greater than women in monogamous marriages who have not been widowed. Disregarding statistical significance, the point estimates suggest that women in polygamous marriages who experience the death of their husband as well as all sister wives have a similar hazard of mortality to women who are widowed in monogamous marriages.

The results shown in Figure 1 show a clear elevated risk of mortality for women in polygamous marriages where the husband and all sister wives have died relative to women in polygamous marriages where all members of the marriage group are alive. Furthermore, the results shown in Figure 1 suggest that the index person's mortality is elevated when some, but not all, members of the marriage group have died relative to none having died, and that the most lethal state is where all members of the marriage group have died. We examine this further by using a simplified version of our marital status variable in additional analyses, which can be seen in Figure 2. Please note again that the estimates shown in the left and right panel are from the same model, where the common reference category is women in monogamous relationships who have not been widowed. Detailed results can be seen in Supplementary Table S2. The results shown in Figure 2 confirm that there is a trend where the death of some members of the marriage group is worse than none, and the death of all members of the marriage group is clearly worst. However, our analyses of women do not show that it is qualitatively worse to experience the death of a husband than the death of a sister wife.

We have also run models to examine whether marriage order in polygamous marriages affects the mortality of women net of the mortality of the husband. We have restricted these analyses to women in plural marriages. Figure 3 shows the results from these analyses, where we apply a husband fixed effect, where first wives are the reference category. In Figure 3, each panel represents a separate analysis, i.e. the models are run separately by completed marriage group size. In these analyses we compare the mortality of women by marriage order nested within the same husband. A detailed table of results including covariates can be found in Tables S3 and S4 in the Supplementary Information. The results from the husband fixed effects models for marriages with two or three sister wives, the vast majority of polygamous marriages, show that 

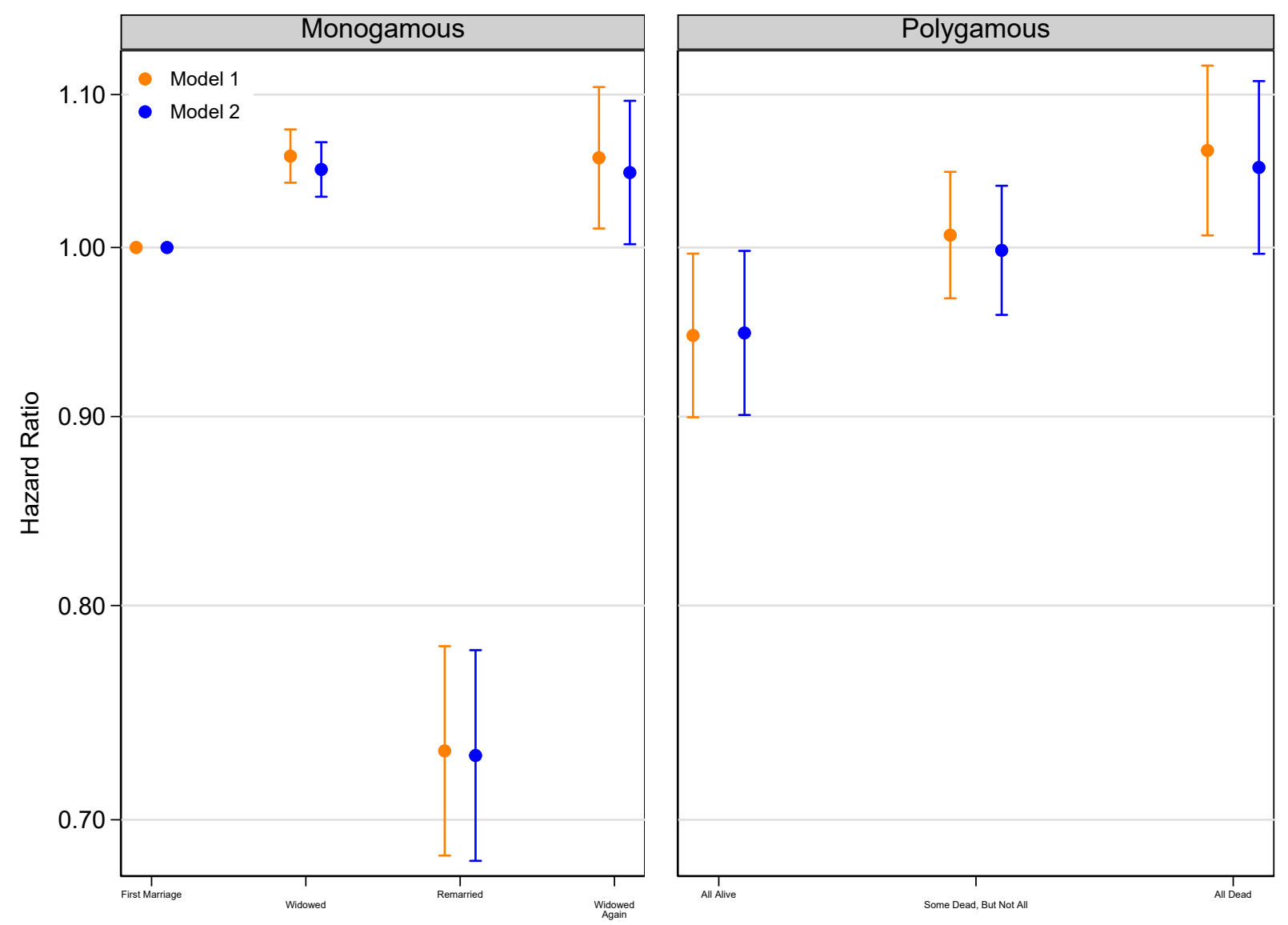

FIGURE 2. Collapsed marital status of women and mortality. Error bars are 95\% confidence intervals. Note that the estimates shown in the left and right panel are from the same model, where the common reference category is women in first monogamous marriages who have not been widowed.

marriage order did not matter for female mortality; higher order wives do not have significantly different mortality from first wives, and the point estimates for second and third order wives are very similar to the reference category. Surprisingly, we see that higher order wives in marriages with four sister wives have much lower mortality, while the point estimates for higher order wives in marriages with five or more sister wives show that they have higher mortality. Given the inconsistencies in these patterns, our overall conclusion is there is no main effect of wife order on female mortality in polygamous marriages. 


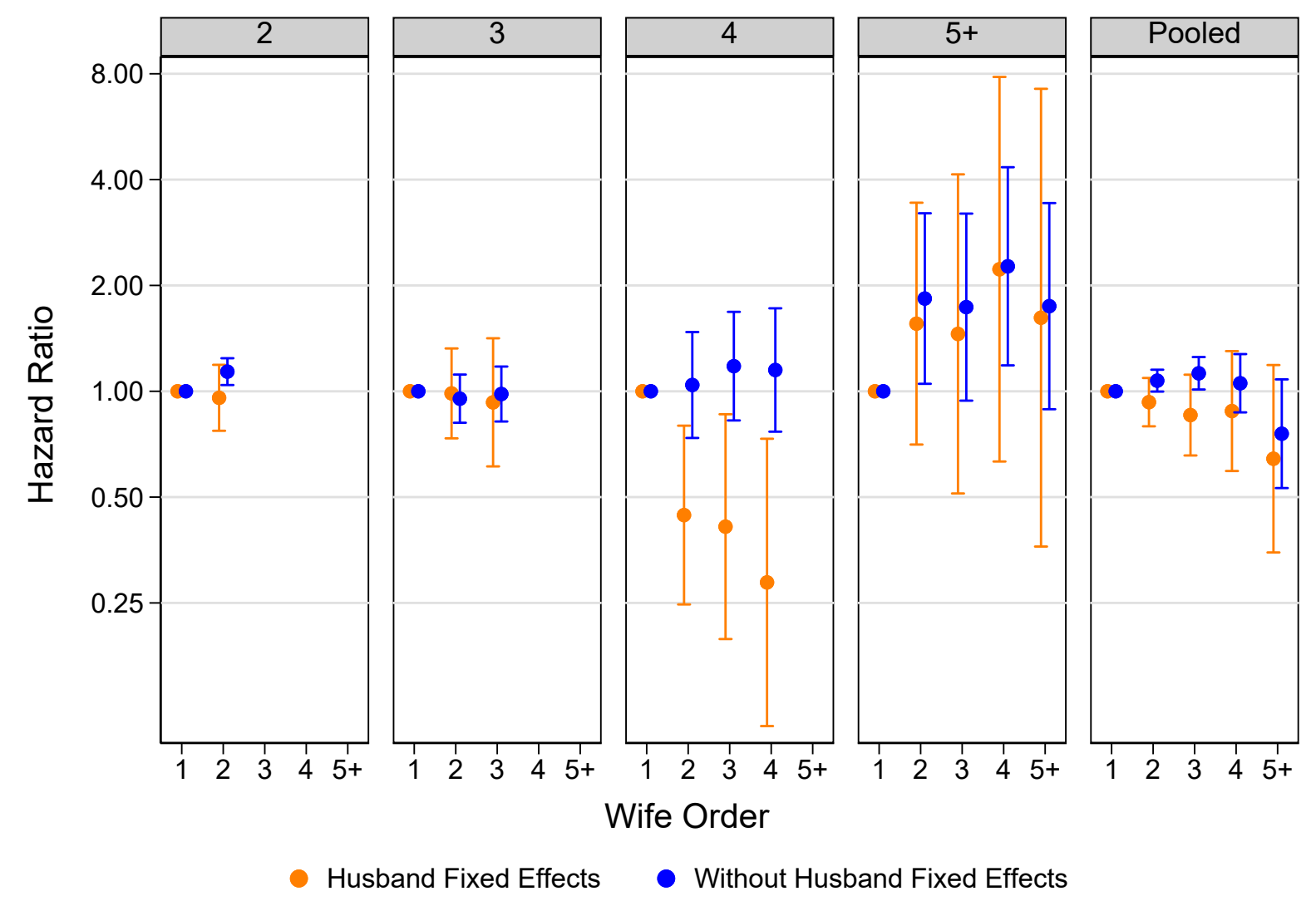

FIGURE 3. Marriage order of women in polygamous marriages and mortality by marriage group size. Error bars are $95 \%$ confidence intervals. Each panel represents a separate analysis by completed marriage group size.

We have also conducted additional analyses where we interact wife order with a time-varying covariate for husband death, in order to examine whether marriage order effects might differ before and after the death of the husband. The results from these analyses can be seen in Figure 4. In Figure 4, each panel represents a separate analysis, i.e. the models are run separately by completed marriage group size. A detailed table of results including covariates can be found in Table S5 in the Supplementary Information. These analyses are also based upon husband fixed effects models. The results from these analyses shows that there was no statistically or substantively meaningful differences in how wife order seems to have been related to the mortality of the index person either before or after the death of the husband. 


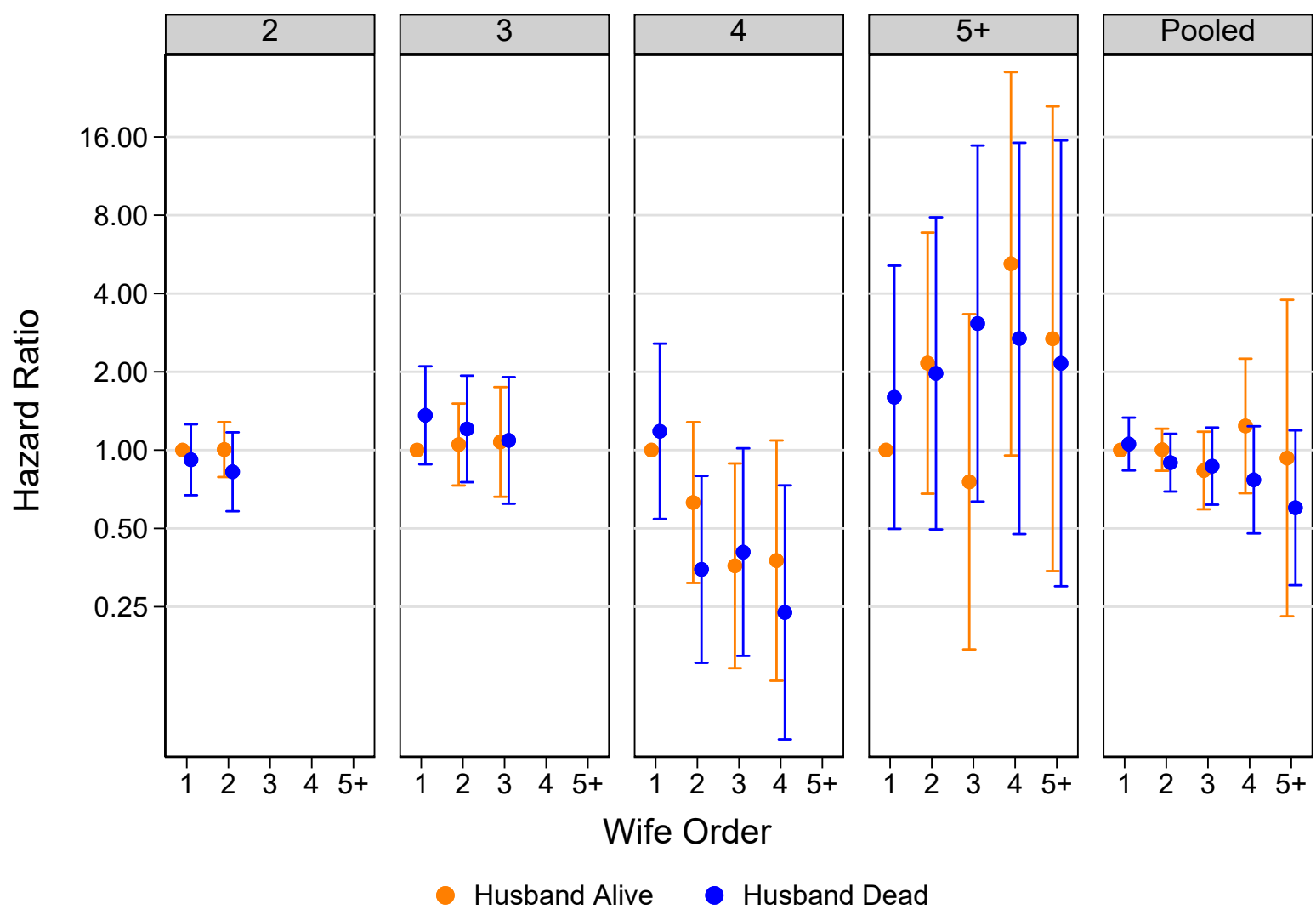

FIGURE 4. Interaction between marriage order of women in polygamous marriages and husband mortality, by marriage group size, applying husband fixed effects. Error bars are 95\% confidence intervals. Each panel represents a separate analysis by completed marriage group size.

Men. The results from multivariate analyses examining the relationship between marital status and mortality are shown for men in Figure 5, while a full table of results can be seen in Supplementary Table S6. Please note again that the estimates shown across the four panels are from the same model, where the common reference category is men in monogamous relationships who have not been widowed. The results from our analyses show that, amongst men in monogamous marriages, being widowed increases the hazard of mortality, while remarriage serves as both a marker of positive selection, as well as the effects of a social support resource that is recovered through remarriage. We observe a sawtooth pattern where men who remarry once or twice following widowhood have monotonically lower mortality both before and after being 


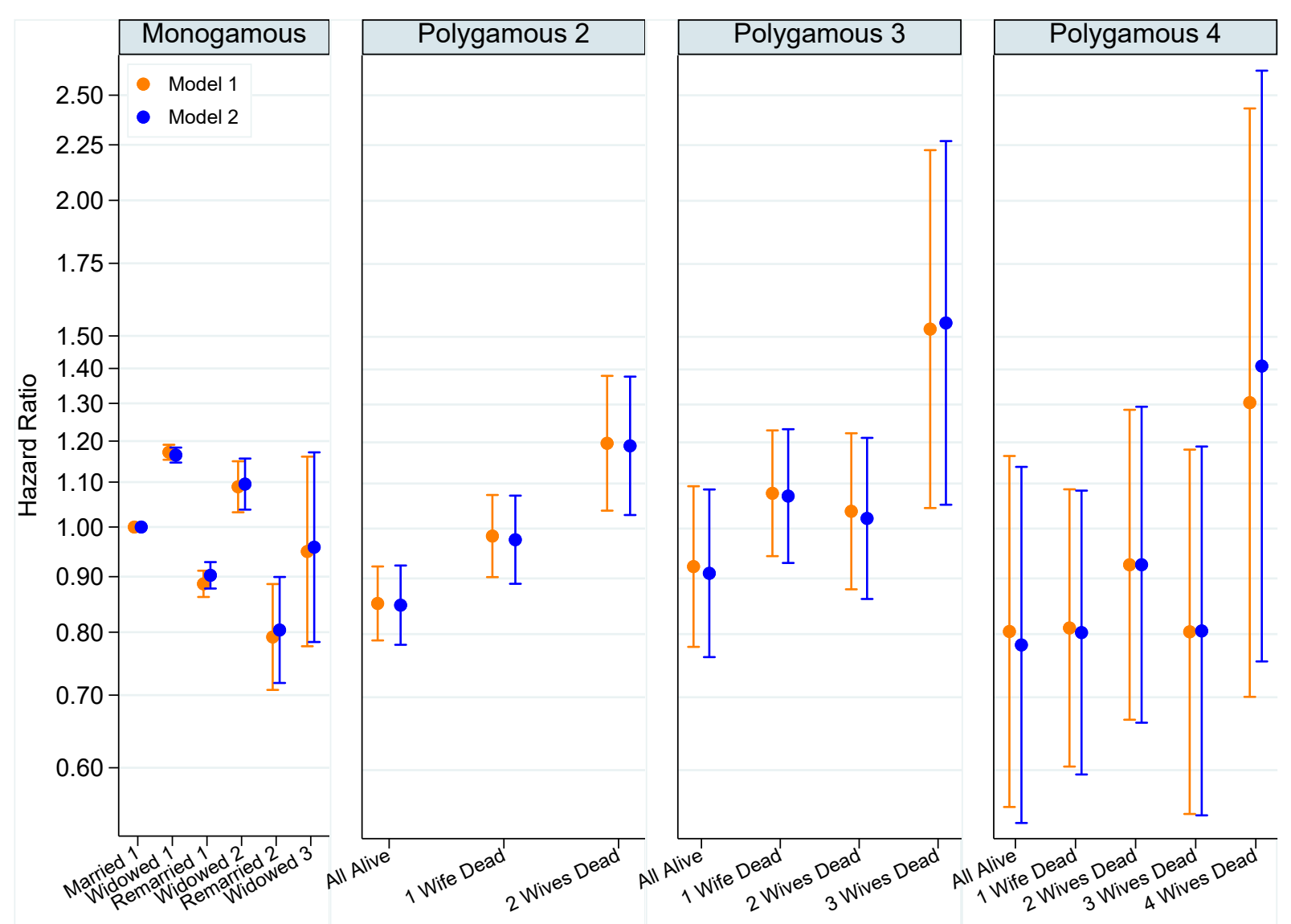

FIGURE 5. Marital status of men and mortality. Error bars are 95\% confidence intervals. Note that the estimates shown across the four panels are from the same model, where the common reference category is men in first monogamous marriages who have not been widowed.

widowed. Presumably men who are widowed but are able to remarry are healthier and may have higher status in a respect that is not captured by our adjustment for occupational status.

Looking across to the panels showing the results for men in polygamous marriages, we see that men in polygamous marriages who have not suffered the deaths of any wives have lower mortality than men in first monogamous marriages that have not been widowed. This pattern persists despite our adjustment for membership of the Church of Jesus Christ of Latter-day Saints, which means that have we accounted for, given our data, the fact that these men in polygamous marriages should not be consumers of alcohol or tobacco. Amongst men in polygamous marriages who have two wives, we can see that losing one wife increases the hazard of 
mortality, and losing a second wife increases it further still; there appears to be a dose-response pattern, where the death of additional wives is incrementally worse. Amongst men with three wives, we see that having one or two wives die increases the hazard of mortality relative to having no wives die, but it is losing all three wives that most dramatically increases the hazard of mortality. Amongst men with four wives, the measurement is much less precise because of the relatively small number of these marriage groups, but we can clearly see that the death of all four wives increases the hazard of mortality for the husband substantially. Indeed, based upon the point estimates, it is worse for men in polygamous marriages to lose all of their wives to mortality than it is for men in monogamous marriages. As with our analyses of women, we find that the estimates are very similar across models 1 and 2, indicating that our variables for socioeconomic status and fertility do not play an important confounding or mediating role in the relationship between marital status and mortality in historical Utah.

These main analyses presented above exclude men who ever had more than four wives. However, we have run additional analyses where we include these men, but top-code the number of wives at 4+. The results from those analyses can be seen in Supplementary Figure S1. The results are qualitatively very similar to those presented directly above.

\section{DISCUSSION}

The results from this study corroborate previous research demonstrating the widowhood mortality effect in historical Utah in monogamous marriages (Mineau et al., 2002), and extend that research by examining polygamous marriages. These results indicate that women in polygamous marriages are not as adversely affected by the death of the husband as women in monogamous marriages are, unless all of the sister wives have died as well. It may be the case that the surviving sister wives provide each other with social and emotional support that reduces the negative impact of a husband death. We can speculate that although the resources in a polygamous marriage would have to be divided amongst a larger number of individuals following 
the death of the husband, the collective social networks of the sister wives may have been successful in drawing in sufficient resources to prevent dramatically poorer living conditions for the surviving members of the polygamous marriage. However, our results also show that the increase in mortality for women in a polygamous marriage when her husband and all of her sister wives have died is relatively greater than it is for women who have been widowed in a monogamous marriage. The death of the husband as well as all of the sister wives is likely to reflect a confluence of negative conditions that substantially increases the hazard of mortality for the surviving woman, including shared environmental factors that increase the mortality of all members of the marriage group, as well as the loss of financial resources, social and emotional support, and extended social networks that had come from the deceased husband and sister wives. Our analyses of marriage order in polygamous marriages showed no statistically significant differences in mortality by order for wives, though the point estimates suggested that third- and higher-order wives may have had lower mortality.

Regarding the results for men, we found that men in polygamous marriages had lower mortality than men in monogamous marriages. Although we do adjust for the occupational status of the man, it is possible that our measure fails to fully capture the advantage associated with the greater resources available to men who were able to take multiple wives. This is further emphasized by the fact that we observe that men in polygamous marriages who have been widowed once have a very similar hazard of mortality to men in monogamous marriages who have not been widowed at all. Relative to men in their respective marriage types who had not experienced spousal death, the overall negative effect of widowhood for men in monogamous and polygamous marriages was similar. However, after examining the effect of losing one wife versus two or more, it was clear that the death of one wife for a man in a polygamous marriage was associated with a lower increase in the hazard of mortality than the death of one wife for a man in a monogamous marriage. 
The fact that losing one wife was less consequential for men in polygamous marriages than in monogamous marriages makes sense from the perspective that the surviving man in a polygamous marriage would still have surviving wives that would be able to offer social and psychological support. Most men in our analytical population in polygamous marriages had two wives. As a result, the death of two wives would mean an equivalent loss of spousal support to the death of one wife for a man in a monogamous marriage, and we found that the increase in mortality for polygamous men with two wives following the death of both wives was approximately equivalent to the increase in mortality associated with widowhood for men in monogamous marriages. The general dose-response pattern that we observe in the analyses of men in polygamous marriages suggests that both confounding and a genuine casual effect may drive our results for men. The increase in the hazard of mortality for men following the death of some, but not all wives, may reflect the contribution of shared hazardous environmental conditions, as well as assortative mating on factors that may increase the hazard of mortality. The death of all wives may reflect even worse shared environmental conditions, but is also consistent with a genuine causal effect of bereavement. Indeed, losing multiple deeply valued family members may well have a more severe negative effect on the surviving husband than losing one.

In general the results that we observed in this study are highly consistent with previous research on this topic, as we observe that the point estimates for the increase in the hazard of mortality associated with spousal death were greater for men than for women (Shor et al., 2012). This is also consistent with the broader literature showing that men experience greater health benefits from marriage than do women, which may be driven by the tendency for women to form stronger social support networks outside of the wife-husband dyad (Stevens, 1995). Our results are also consistent with previous research that has shown that the widowhood mortality effect was often weaker in historical contexts than it has been observed to be in contemporary contexts (Shor et al., 2012). In a number of senses this is surprising, as 19th century Utah would have been a relatively less forgiving environment in which to lose critical social and economic support. However, it is possible that there may have been greater support from the Church, local 
community, or from kin in these historical settings. Previous research using historical data from the Netherlands has found that the death of a husband was particularly detrimental for women when they had multiple children (Alter et al., 2007). Our finding that adjusting for biological parity makes very little difference to the estimates suggests that there may have been some other kind of support available in Utah to help mitigate the costs associated with providing for so many mouths. It should also be noted that that the harsh conditions of 19th century Utah meant that baseline mortality hazard rates were high, even for the monogamous couples. Although widowhood is clearly bad for the surviving spouse, in a context where baseline mortality rates are already very high, even an adverse exposure may not be able to increase the baseline rate by the same relative degree as it would in a low mortality context.

Although this study has been focused upon polygamous relationships, a clear and consistent finding has been that individuals in monogamous marriages who were widowed but remarried had lower mortality than those in a first monogamous marriage, a result that was also observed in a previous study using the Utah Population Database (Mineau et al., 2002). Although it is not clear how we would be able to test this directly with this dataset, this pattern is likely to have been produced by selection processes. Men and women who were able to find a new marriage partner after the death of the first spouse are likely to have been characterised by some combination of physical attractiveness, ample material resources, good health, and youth. This could explain why they would have lower mortality than those who were widowed and did not find a new marriage partner, but could also explain why they would even have lower mortality than those in a first marriage. A more surprising result is that we observed no significant differences in the hazards of mortality by marriage order. Previous research has suggested that there is a hierarchy of influence and status amongst women in polygamous marriages, and that this has a tangible influence on the health of the wife as well as her children (Gibson and Mace, 2007; Bove and Valeggia, 2009). Future research might explore this dynamic further by examining how both fertility and the mortality of children varies by the marriage order of the mother in 
polygamous marriages both before and after widowhood. Since children, and particularly infants, are likely to be more vulnerable to resource scarcity, this might provide some insights into how resources are distributed by wife marriage order within the household before and after the death of the husband.

\section{REFERENCES}

Al-Krenawi, A. (2014), Psychosocial Impact of Polygamy in the Middle East, Springer. Allison, P. D. (2009), Fixed Effects Regression Models, vol. 160, SAGE Publications.

Alter, G., Dribe, M. and Van Poppel, F. (2007), 'Widowhood, family size, and post-reproductive mortality: a comparative analysis of three populations in nineteenth-century europe', Demography 44(4), 785-806.

Antonucci, T. C. and Akiyama, H. (1987), 'An examination of sex differences in social support among older men and women', Sex Roles 17(11-12), 737-749.

Arrington, L. J. and May, D. (1975), "” a different mode of life": Irrigation and society in nineteenth-century utah', Agricultural History 49(1), 3-20.

Bean, L. L. and Mineau, G. P. (1986), 'The polygyny-fertility hypothesis: a re-evaluation', Population Studies 40(1), 67-81.

Bean, L. L., Mineau, G. P. and Anderton, D. L. (1990), Fertility Change on the American Frontier: Adaptation and Innovation, University of California Press, Berkeley.

Bledsoe, C. (1990), 'Transformations in sub-saharan african marriage and fertility', The Annals of the American Academy of Political and Social Science pp. 115-125.

Bove, R. and Valeggia, C. (2009), 'Polygyny and women's health in sub-saharan africa', Social Science \& Medicine 68(1), 21-29.

Bush, L. E. (1993), Health and Medicine Among the Latter-Day Saints, Crossroad, New York.

Bushman, R. L. (2008), Mormonism: A Very Short Introduction, Oxford University Press, Oxford.

Campbell, C. and Lee, J. Z. (1996), 'A death in the family: Household structure and mortality in rural liaoning: Life-event and time-series analysis, 1792-1867', The History of the Family 1(3), 297-328.

Cox, D. R. (1972), 'Regression models and life-tables', Journal of the Royal Statistical Society, Series B 34(2), 187-220.

Drefahl, S. (2010), 'How does the age gap between partners affect their survival?', Demography 47(2), 313-326.

Drefahl, S. (2012), 'Do the married really live longer? the role of cohabitation and socioeconomic status', Journal of Marriage and Family 74(3), 462-475.

Elwert, F. and Christakis, N. A. (2006), 'Widowhood and race', American Sociological Review 71(1), 16-41.

Elwert, F. and Christakis, N. A. (2008a), 'The effect of widowhood on mortality by the causes of death of both spouses', American Journal of Public Health 98(11), 2092-2098.

Elwert, F. and Christakis, N. A. (2008b), 'Wives and ex-wives: A new test for homogamy bias in the widowhood effect', Demography 45(4), 851-873. 
Friedlander, N. J. (1996), 'The relation of lifetime reproduction to survivorship in women and men: A prospective study', American Journal of Human Biology 8(6), 771-783.

Gibson, M. A. and Mace, R. (2007), 'Polygyny, reproductive success and child health in rural ethiopia: why marry a married man?', Journal of Biosocial Science 39(02), 287-300.

Goldman, N. (1993), 'Marriage selection and mortality patterns: inferences and fallacies', Demography 30(2), 189-208.

Gordon, S. B. (2002), The Mormon Question: Polygamy and Constitutional Conflict in Nineteenth-century America, University of North Carolina Press, Chapel Hill, NC.

Hanson, H. and Smith, K. (2013), 'Early origins of longevity: Prenatal exposures to food shortage among early utah pioneers', Journal of Developmental Origins of Health and Disease 4(2), 170-181.

House, J. S., Umberson, D. and Landis, K. R. (1988), 'Structures and processes of social support', Annual Review of Sociology pp. 293-318.

$\mathrm{Hu}$, Y. and Goldman, N. (1990), 'Mortality differentials by marital status: an international comparison', Demography 27(2), 233-250.

Hurt, L. S., Ronsmans, C. and Thomas, S. L. (2006), ‘The effect of number of births on women's mortality: systematic review of the evidence for women who have completed their childbearing', Population Studies 60(1), 55-71.

Jacoby, H. G. (1995), 'The economics of polygyny in sub-saharan africa: Female productivity and the demand for wives in côte d'ivoire', Journal of Political Economy pp. 938-971.

Jankowiak, W., Sudakov, M. and Wilreker, B. C. (2005), 'Co-wife conflict and co-operation', Ethnology pp. 81-98.

Jin, L. and Chrisatakis, N. A. (2009), 'Investigating the mechanism of marital mortality reduction: the transition to widowhood and quality of health care', Demography 46(3), 605-625.

Josephson, S. C. (2002), 'Does polygyny reduce fertility?', American Journal of Human Biology 14(2), 222-232.

Lawson, D. W., James, S., Ngadaya, E., Ngowi, B., Mfinanga, S. G. and Mulder, M. B. (2015), 'No evidence that polygynous marriage is a harmful cultural practice in northern tanzania', Proceedings of the National Academy of Sciences 112(45), 13827-13832.

Lewis, D. R., Southwick, J. W., Ouellet-Hellstrom, R., Rench, J. and Calderon, R. L. (1999), 'Drinking water arsenic in utah: A cohort mortality study.', Environmental Health Perspectives 107(5), 359.

Lillard, L. A. and Waite, L. J. (1995), 'til death do us part: Marital disruption and mortality', American Journal of Sociology pp. 1131-1156.

Lin, D. Y. and Wei, L.-J. (1989), 'The robust inference for the cox proportional hazards model', Journal of the American Statistical Association 84(408), 1074-1078.

Mammen, K. (2009), All for one or each for her own: Do polygamous families share and share alike?

URL: http://qc-econ-bba.com/seminarpapers/3-29-12.pdf

Martikainen, P. and Valkonen, T. (1996), 'Mortality after death of spouse in relation to duration of bereavement in finland.', Journal of Epidemiology and Community Health 50(3), 264-268.

Mastekaasa, A. (1992), 'Marriage and psychological well-being: Some evidence on selection into marriage', Journal of Marriage and the Family pp. 901-911. 
McPherson, M., Smith-Lovin, L. and Cook, J. M. (2001), 'Birds of a feather: homophily in social networks', Annual Review of Sociology 27, 415-444.

Mineau, G. P., Smith, K. R. and Bean, L. L. (2002), 'Historical trends of survival among widows and widowers', Social Science \& Medicine 54(2), 245-254.

Moorad, J. A., Promislow, D. E., Smith, K. R. and Wade, M. J. (2011), 'Mating system change reduces the strength of sexual selection in an american frontier population of the 19th century', Evolution and Human Behavior 32(2), 147-155.

Mulder, M. B. (1989), 'Marital status and reproductive performance in kipsigis women: reevaluating the polygyny-fertility hypothesis', Population Studies 43(2), 285-304.

Murdock, G. P. and White, D. R. (1969), 'Standard cross-cultural sample', Ethnology 8(4), 329369.

Murray, J. E. (2000), 'Marital protection and marital selection: Evidence from a historicalprospective sample of american men', Demography 37(4), 511-521.

Nam, C. B. and Boyd, M. (2004), 'Occupational status in 2000; over a century of census-based measurement', Population Research and Policy Review 23(4), 327-358.

Nomaguchi, K. M. and Bianchi, S. M. (2004), 'Exercise time: Gender differences in the effects of marriage, parenthood, and employment', Journal of Marriage and Family 66(2), 413-430.

Nystedt, P. (2002), 'Widowhood-related mortality in scania, sweden during the 19th century', The History of the Family 7(3), 451-478.

O'Bryant, S. L. (1988), 'Sibling support and older widows' well-being', Journal of Marriage and the Family 50(1), 173-183.

Shor, E., Roelfs, D. J., Curreli, M., Clemow, L., Burg, M. M. and Schwartz, J. E. (2012), 'Widowhood and mortality: a meta-analysis and meta-regression', Demography 49(2), 575606.

Smith-Greenaway, E. and Trinitapoli, J. (2014), 'Polygynous contexts, family structure, and infant mortality in sub-saharan africa', Demography 51(2), 341-366.

Smith, J. E. and Kunz, P. R. (1976), 'Polygyny and fertility in nineteenth-century america', Population Studies 30(3), 465-480.

Smith, K. P. and Christakis, N. A. (2008), 'Social networks and health', Annual Review of Sociology 34, 405-429.

Smith, K. R., Mineau, G. P. and Bean, L. L. (2002), 'Fertility and post-reproductive longevity', Biodemography and Social Biology 49(3-4), 185-205.

Smith, K. R. and Zick, C. D. (1994), 'Linked lives, dependent demise? survival analysis of husbands and wives', Demography 31(1), 81-93.

Smith, K. R. and Zick, C. D. (1996), 'Risk of mortality following widowhood: Age and sex differences by mode of death', Social Biology 43(1-2), 59-71.

Stevens, N. (1995), 'Gender and adaptation to widowhood in later life', Ageing \& society 15(1), 37-58.

Strassmann, B. I. (1997), 'Polygyny as a risk factor for child mortality among the dogon', Current Anthropology 38(4), 688-695.

Stroebe, M., Schut, H. and Stroebe, W. (2007), 'Health outcomes of bereavement', The Lancet 370(9603), 1960-1973.

Stutzer, A. and Frey, B. S. (2006), 'Does marriage make people happy, or do happy people get married?', The Journal of Socio-Economics 35(2), 326-347. 
Umberson, D. (1987), 'Family status and health behaviors: social control as a dimension of social integration', Journal of Health and Social Behavior pp. 306-319.

Umberson, D. (1992), 'Gender, marital status and the social control of health behavior', Social Science \& Medicine 34(8), 907-917.

Umberson, D., Williams, K., Powers, D. A., Liu, H. and Needham, B. (2006), 'You make me sick: Marital quality and health over the life course', Journal of Health and Social Behavior 47(1), 1-16.

Umberson, D., Wortman, C. B. and Kessler, R. C. (1992), 'Widowhood and depression: Explaining long-term gender differences in vulnerability', Journal of Health and Social Behavior pp. 10-24.

Van Poppel, F. and Joung, I. (2001), 'Long-term trends in marital status mortality differences in the netherlands 1850-1970', Journal of Biosocial Science 33(2), 279-303.

Welch, A. H., Lico, M. S. and Hughes, J. L. (1988), 'Arsenic in ground water of the western united states', Groundwater 26(3), 333-347. 
SUPPLEMENTARY INFORMATION 
TABLE S1. Women: marital status and mortality.

\begin{tabular}{|c|c|c|c|c|c|c|c|}
\hline & & \multicolumn{3}{|c|}{ Model 1} & \multicolumn{3}{|c|}{ Model 2} \\
\hline & & HR & SE & $95 \% \mathrm{CI}$ & HR & $\mathrm{SE}$ & $95 \% \mathrm{CI}$ \\
\hline \multirow[t]{10}{*}{ Marital status } & Monogamous, first marriage (ref) & 1.00 & & & 1.00 & & \\
\hline & Monogamous, first widowhood & 1.06 & 0.01 & $1.04-1.08$ & 1.05 & 0.01 & $1.03-1.07$ \\
\hline & Monogamous, remarried & 0.73 & 0.02 & $0.68-0.78$ & 0.73 & 0.02 & $0.68-0.78$ \\
\hline & Monogamous, widowed again & 1.06 & 0.02 & $1.01-1.11$ & 1.05 & 0.02 & $1.00-1.10$ \\
\hline & Polygamous, husband and all sister wives alive & 0.95 & 0.02 & $0.90-1.00$ & 0.95 & 0.02 & $0.90-1.00$ \\
\hline & Polygamous, husband alive, some sister wives dead & 0.95 & 0.05 & $0.85-1.06$ & 0.95 & 0.05 & $0.85-1.06$ \\
\hline & Polygamous, husband alive, all sister wives dead & 1.03 & 0.06 & $0.92-1.16$ & 1.03 & 0.06 & $0.91-1.16$ \\
\hline & Polygamous, husband dead, all sister wives alive & 0.99 & 0.03 & $0.93-1.05$ & 0.98 & 0.03 & $0.93-1.04$ \\
\hline & Polygamous, husband dead, some sister wvies dead & 1.04 & 0.03 & $0.98-1.10$ & 1.02 & 0.03 & $0.96-1.08$ \\
\hline & Polygamous, husband and all sister wives dead & 1.06 & 0.03 & $1.01-1.12$ & 1.05 & 0.03 & $1.00-1.11$ \\
\hline \multirow[t]{11}{*}{ Birth cohort } & $<1800$ & 1.33 & 0.05 & $1.23-1.44$ & 1.32 & 0.05 & $1.22-1.43$ \\
\hline & 1800-1809 & 1.25 & 0.04 & $1.17-1.33$ & 1.24 & 0.04 & $1.16-1.32$ \\
\hline & $1810-1819$ & 1.43 & 0.03 & $1.37-1.50$ & 1.42 & 0.04 & $1.35-1.49$ \\
\hline & $1820-1829$ & 1.39 & 0.03 & $1.33-1.44$ & 1.38 & 0.03 & $1.32-1.44$ \\
\hline & $1830-1839$ & 1.32 & 0.02 & $1.28-1.37$ & 1.32 & 0.02 & $1.28-1.37$ \\
\hline & $1840-1849$ & 1.29 & 0.02 & $1.26-1.33$ & 1.30 & 0.02 & $1.26-1.34$ \\
\hline & $1850-1859$ & 1.24 & 0.02 & $1.21-1.27$ & 1.24 & 0.02 & $1.21-1.27$ \\
\hline & $1860-1869$ & 1.20 & 0.01 & $1.17-1.22$ & 1.19 & 0.01 & $1.16-1.21$ \\
\hline & $1870-1879$ & 1.14 & 0.01 & $1.11-1.16$ & 1.13 & 0.01 & $1.11-1.15$ \\
\hline & $1880-1889$ (ref) & 1.00 & & & 1.00 & & \\
\hline & $1890-1900$ & 0.81 & 0.01 & $0.79-0.82$ & 0.81 & 0.01 & $0.80-0.83$ \\
\hline \multirow[t]{3}{*}{ LDS membership } & Non-member (ref) & 1.00 & & & 1.00 & & \\
\hline & Inactive & 0.90 & 0.01 & $0.88-0.93$ & 0.90 & 0.01 & $0.88-0.92$ \\
\hline & Active & 0.93 & 0.01 & $0.92-0.95$ & 0.93 & 0.01 & $0.91-0.95$ \\
\hline Age difference between & $<-9$ & & & & 1.01 & 0.01 & $0.99-1.03$ \\
\hline \multirow[t]{6}{*}{ wife and husband } & -9 to -5 & & & & 1.00 & 0.01 & $0.98-1.02$ \\
\hline & -4 to -1 & & & & 1.00 & 0.01 & $0.98-1.02$ \\
\hline & -1 to 1 (ref) & & & & 1.00 & & \\
\hline & 1 to 4 & & & & 1.02 & 0.02 & $0.98-1.05$ \\
\hline & 5 to 9 & & & & 1.02 & 0.03 & $0.96-1.07$ \\
\hline & $>9$ & & & & 0.96 & 0.06 & $0.85-1.08$ \\
\hline \multirow[t]{11}{*}{ Biological parity } & 0 (ref) & & & & 1.00 & & \\
\hline & 1 & & & & 0.92 & 0.02 & $0.89-0.95$ \\
\hline & 2 & & & & 0.91 & 0.01 & $0.88-0.94$ \\
\hline & 3 & & & & 0.90 & 0.01 & $0.87-0.92$ \\
\hline & 4 & & & & 0.92 & 0.01 & $0.89-0.95$ \\
\hline & 5 & & & & 0.90 & 0.01 & $0.88-0.93$ \\
\hline & 6 & & & & 0.90 & 0.01 & $0.87-0.93$ \\
\hline & 7 & & & & 0.92 & 0.02 & $0.89-0.95$ \\
\hline & 8 & & & & 0.92 & 0.02 & $0.89-0.95$ \\
\hline & 9 & & & & 0.92 & 0.02 & $0.89-0.95$ \\
\hline & $10+$ & & & & 0.93 & 0.01 & $0.91-0.96$ \\
\hline \multirow[t]{2}{*}{ Born outside of Utah } & No (ref) & & & & 1.00 & & \\
\hline & Yes & & & & 0.97 & 0.01 & $0.95-0.98$ \\
\hline Husband Nam-Powers & 1 & & & & 1.05 & 0.05 & $0.97-1.14$ \\
\hline \multirow[t]{10}{*}{ score } & 2 & & & & 1.01 & 0.03 & $0.96-1.07$ \\
\hline & 3 & & & & 1.06 & 0.02 & $1.03-1.10$ \\
\hline & 4 & & & & 1.03 & 0.02 & $0.98-1.08$ \\
\hline & 5 (ref) & & & & 1.00 & & \\
\hline & 6 & & & & 1.02 & 0.02 & $0.98-1.06$ \\
\hline & 7 & & & & 0.94 & 0.02 & $0.90-0.98$ \\
\hline & 8 & & & & 0.94 & 0.02 & $0.91-0.97$ \\
\hline & 9 & & & & 0.90 & 0.02 & $0.86-0.94$ \\
\hline & 10 & & & & 0.86 & 0.02 & $0.82-0.90$ \\
\hline & Missing & & & & 1.04 & 0.01 & $1.01-1.07$ \\
\hline \multirow[t]{2}{*}{ Husband farmer } & No (ref) & & & & 1.00 & & \\
\hline & Yes & & & & 1.01 & 0.01 & $0.99-1.04$ \\
\hline \multirow{2}{*}{\multicolumn{2}{|c|}{$\begin{array}{l}\mathrm{N} \\
\text { Deaths }\end{array}$}} & \multicolumn{3}{|c|}{110,952} & \multicolumn{3}{|c|}{110,952} \\
\hline & & \multicolumn{3}{|c|}{107,905} & \multicolumn{3}{|c|}{107,905} \\
\hline
\end{tabular}


TABLE S2. Women: marital status and mortality.

\begin{tabular}{|c|c|c|c|c|c|c|c|}
\hline & & \multicolumn{3}{|c|}{ Model 1} & \multicolumn{3}{|c|}{ Model 2} \\
\hline & & HR & SE & $95 \% \mathrm{CI}$ & HR & SE & $95 \% \mathrm{CI}$ \\
\hline \multirow[t]{7}{*}{ Marital status } & Monogamous, first marriage (ref) & 1.00 & & & 1.00 & & \\
\hline & Monogamous, first widowhood & 1.06 & 0.01 & $1.04-1.08$ & 1.05 & 0.01 & $1.03-1.07$ \\
\hline & Monogamous, remarried & 0.73 & 0.02 & $0.68-0.78$ & 0.73 & 0.02 & $0.68-0.78$ \\
\hline & Monogamous, widowed again & 1.06 & 0.02 & $1.01-1.11$ & 1.05 & 0.02 & $1.00-1.10$ \\
\hline & Polygamous, husband and all sister wives alive & 0.95 & 0.02 & $0.90-1.00$ & 0.95 & 0.02 & $0.90-1.00$ \\
\hline & Polygamous, some household members dead & 1.01 & 0.02 & $0.97-1.05$ & 1.00 & 0.02 & $0.96-1.04$ \\
\hline & Polygamous, husband and all sister wives dead & 1.06 & 0.03 & $1.01-1.12$ & 1.05 & 0.03 & $1.00-1.11$ \\
\hline \multirow[t]{11}{*}{ Birth cohort } & $<1800$ & 1.33 & 0.05 & $1.23-1.44$ & 1.32 & 0.05 & $1.22-1.43$ \\
\hline & $1800-1809$ & 1.25 & 0.04 & $1.17-1.33$ & 1.24 & 0.04 & $1.16-1.32$ \\
\hline & $1810-1819$ & 1.43 & 0.03 & $1.37-1.50$ & 1.42 & 0.04 & $1.35-1.49$ \\
\hline & $1820-1829$ & 1.39 & 0.03 & $1.33-1.44$ & 1.38 & 0.03 & $1.32-1.44$ \\
\hline & $1830-1839$ & 1.32 & 0.02 & $1.28-1.37$ & 1.32 & 0.02 & $1.28-1.37$ \\
\hline & $1840-1849$ & 1.29 & 0.02 & $1.26-1.33$ & 1.30 & 0.02 & $1.26-1.34$ \\
\hline & $1850-1859$ & 1.24 & 0.02 & $1.21-1.27$ & 1.24 & 0.02 & $1.21-1.27$ \\
\hline & $1860-1869$ & 1.20 & 0.01 & $1.17-1.22$ & 1.19 & 0.01 & $1.16-1.21$ \\
\hline & $1870-1879$ & 1.14 & 0.01 & $1.11-1.16$ & 1.13 & 0.01 & $1.11-1.15$ \\
\hline & $1880-1889$ (ref) & 1.00 & & & 1.00 & & \\
\hline & $1890-1900$ & 0.81 & 0.01 & $0.79-0.82$ & 0.81 & 0.01 & $0.80-0.83$ \\
\hline \multirow{3}{*}{ LDS membership } & Non-member (ref) & 1.00 & & & 1.00 & & \\
\hline & Inactive & 0.90 & 0.01 & $0.88-0.93$ & 0.90 & 0.01 & $0.88-0.92$ \\
\hline & Active & 0.93 & 0.01 & $0.92-0.95$ & 0.93 & 0.01 & $0.91-0.95$ \\
\hline Age difference between & $<-9$ & & & & 1.01 & 0.01 & $0.99-1.03$ \\
\hline \multirow{6}{*}{ wife and husband } & -9 to -5 & & & & 1.00 & 0.01 & $0.98-1.02$ \\
\hline & -4 to -1 & & & & 1.00 & 0.01 & $0.98-1.02$ \\
\hline & -1 to 1 (ref) & & & & 1.00 & & \\
\hline & 1 to 4 & & & & 1.02 & 0.02 & $0.98-1.05$ \\
\hline & 5 to 9 & & & & 1.02 & 0.03 & $0.96-1.07$ \\
\hline & $>9$ & & & & 0.96 & 0.06 & $0.85-1.08$ \\
\hline \multirow[t]{11}{*}{ Biological parity } & 0 (ref) & & & & 1.00 & & \\
\hline & 1 & & & & 0.92 & 0.02 & $0.89-0.95$ \\
\hline & 2 & & & & 0.91 & 0.01 & $0.88-0.94$ \\
\hline & 3 & & & & 0.90 & 0.01 & $0.87-0.92$ \\
\hline & 4 & & & & 0.92 & 0.01 & $0.89-0.95$ \\
\hline & 5 & & & & 0.90 & 0.01 & $0.88-0.93$ \\
\hline & 6 & & & & 0.90 & 0.01 & $0.87-0.93$ \\
\hline & 7 & & & & 0.92 & 0.02 & $0.89-0.95$ \\
\hline & 8 & & & & 0.92 & 0.02 & $0.89-0.95$ \\
\hline & 9 & & & & 0.92 & 0.02 & $0.89-0.95$ \\
\hline & $10+$ & & & & 0.93 & 0.01 & $0.91-0.96$ \\
\hline \multirow[t]{2}{*}{ Born outside of Utah } & No (ref) & & & & 1.00 & & \\
\hline & Yes & & & & 0.97 & 0.01 & $0.95-0.98$ \\
\hline Husband Nam-Powers & 1 & & & & 1.05 & 0.05 & $0.97-1.14$ \\
\hline \multirow[t]{10}{*}{ score } & 2 & & & & 1.01 & 0.03 & $0.96-1.07$ \\
\hline & 3 & & & & 1.06 & 0.02 & $1.03-1.10$ \\
\hline & 4 & & & & 1.03 & 0.02 & $0.98-1.08$ \\
\hline & 5 (ref) & & & & 1.00 & & \\
\hline & 6 & & & & 1.02 & 0.02 & $0.98-1.06$ \\
\hline & 7 & & & & 0.94 & 0.02 & $0.90-0.98$ \\
\hline & 8 & & & & 0.94 & 0.02 & $0.91-0.97$ \\
\hline & 9 & & & & 0.90 & 0.02 & $0.86-0.94$ \\
\hline & 10 & & & & 0.86 & 0.02 & $0.82-0.90$ \\
\hline & Missing & & & & 1.04 & 0.01 & $1.01-1.07$ \\
\hline \multirow[t]{2}{*}{ Husband farmer } & No (ref) & & & & 1.00 & & \\
\hline & Yes & & & & 1.01 & 0.01 & $0.99-1.04$ \\
\hline \multirow{2}{*}{\multicolumn{2}{|c|}{$\begin{array}{l}\mathrm{N} \\
\text { Deaths }\end{array}$}} & \multicolumn{3}{|c|}{110,952} & \multicolumn{3}{|c|}{110,952} \\
\hline & & \multicolumn{3}{|c|}{107,905} & \multicolumn{3}{|c|}{107,905} \\
\hline
\end{tabular}




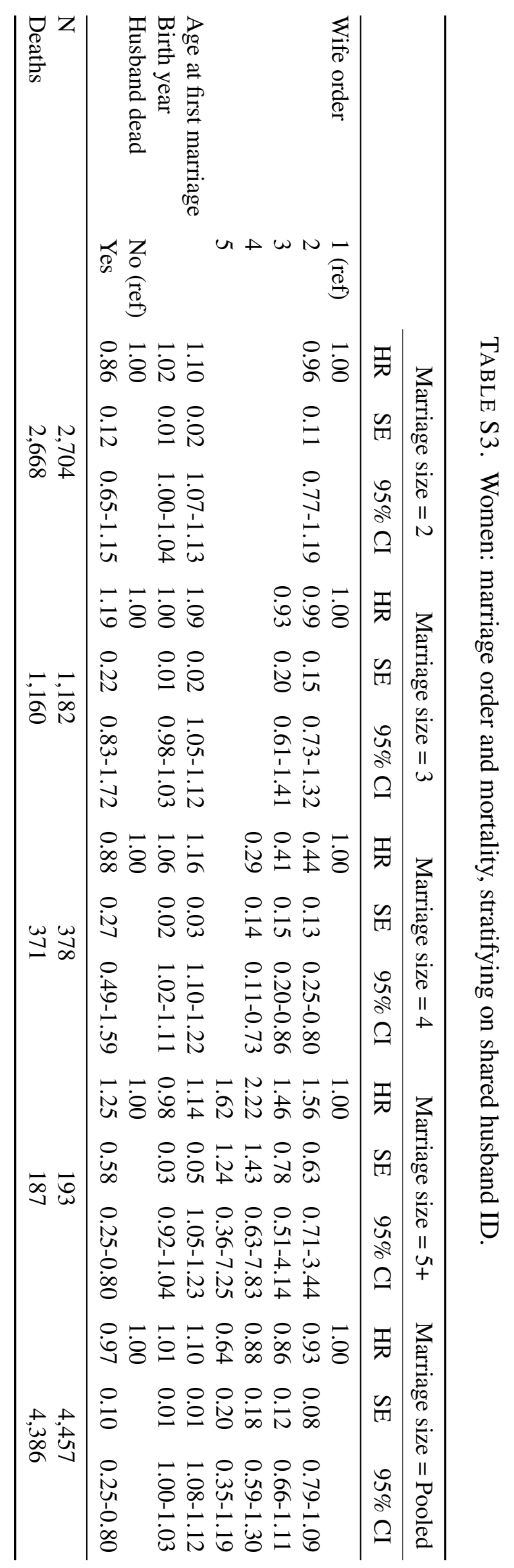




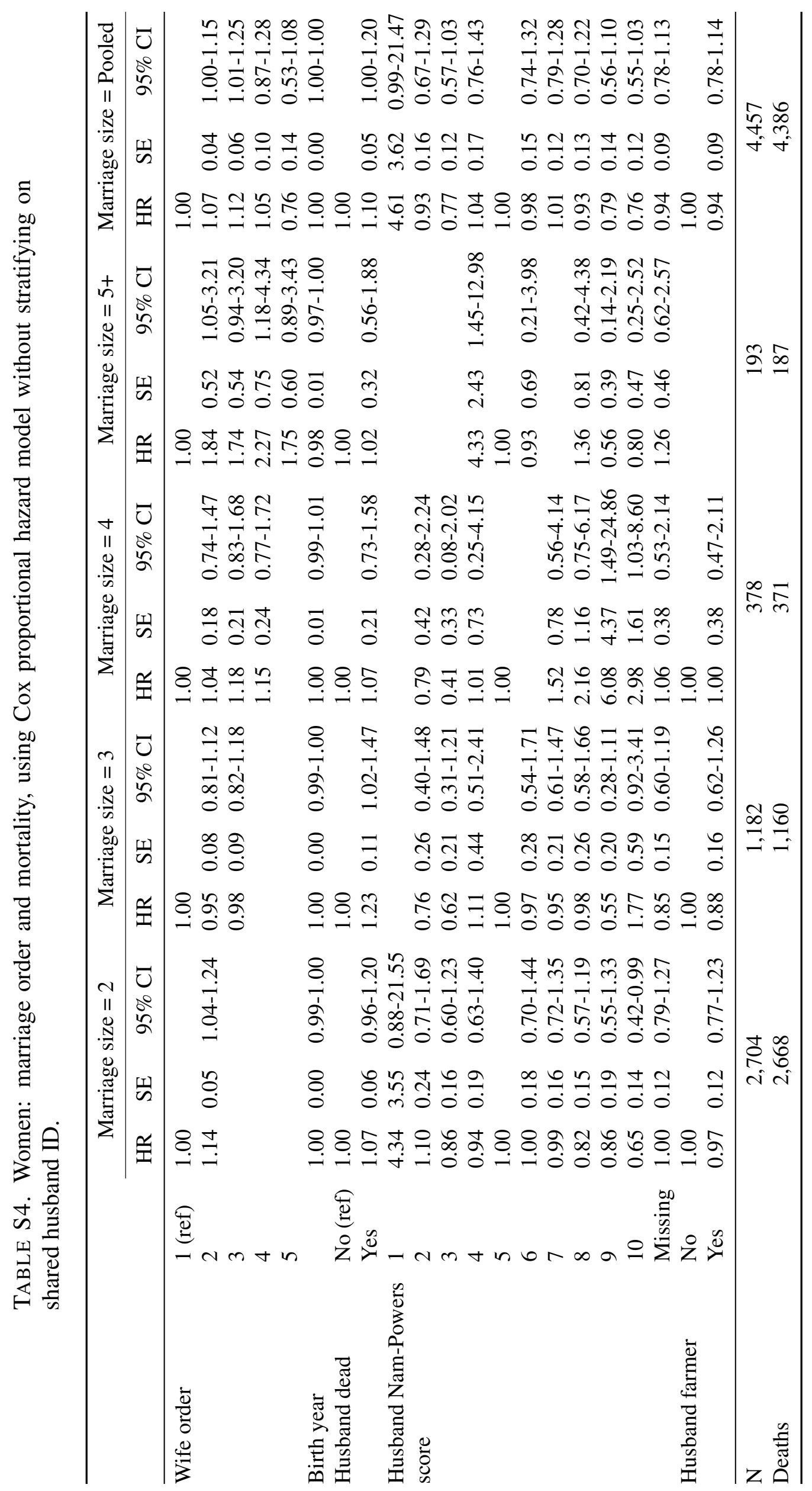




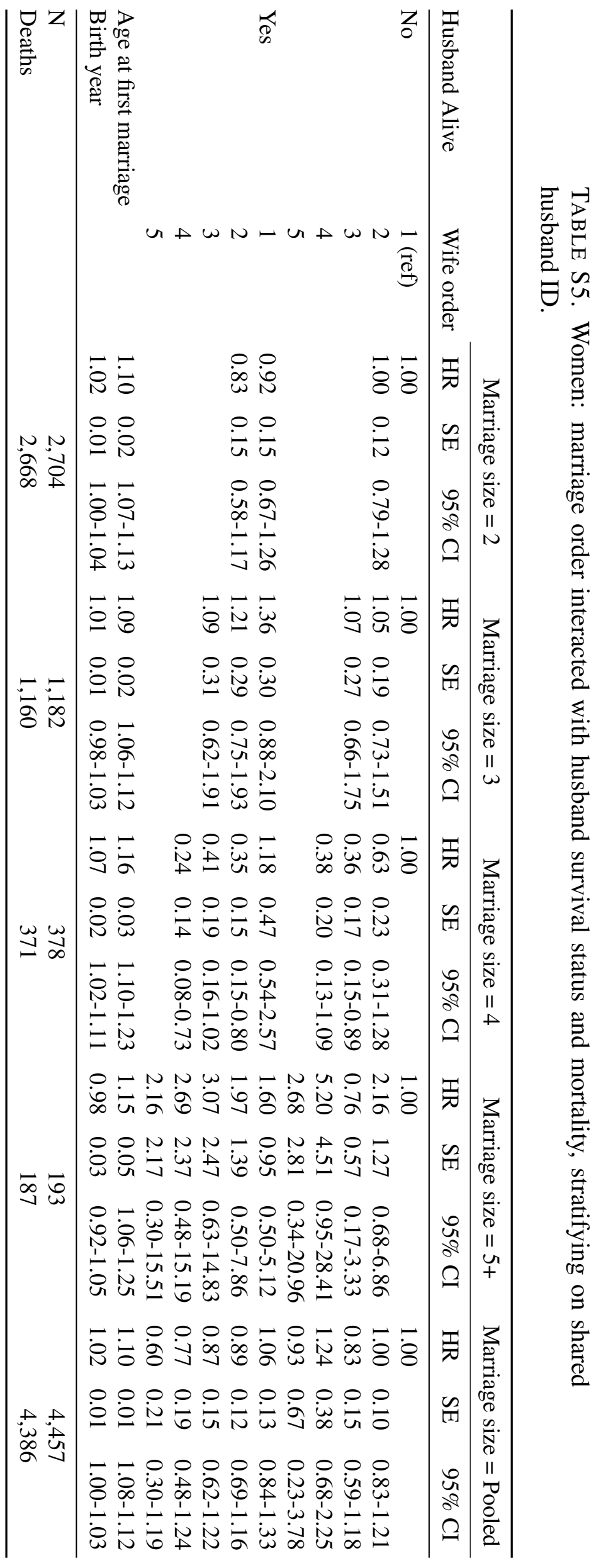


TABLE S6. Men: marital status and mortality.

\begin{tabular}{|c|c|c|c|c|c|c|c|}
\hline & & \multicolumn{3}{|c|}{ Model 1} & \multicolumn{3}{|c|}{ Model 2} \\
\hline & & HR & SE & $95 \% \mathrm{CI}$ & HR & SE & $95 \% \mathrm{CI}$ \\
\hline \multirow[t]{18}{*}{ Marital status } & Monogamous, first marriage & 1.00 & & & 1.00 & & \\
\hline & Monogamous, first widowhood & 1.17 & 0.01 & $1.15-1.19$ & 1.17 & 0.01 & $1.15-1.18$ \\
\hline & Monogamous, second marriage & 0.89 & 0.01 & $0.86-0.91$ & 0.90 & 0.01 & $0.88-0.93$ \\
\hline & Monogamous, second widowhood & 1.09 & 0.03 & $1.03-1.15$ & 1.10 & 0.03 & $1.04-1.16$ \\
\hline & Monogamous, third marriage & 0.79 & 0.05 & $0.71-0.89$ & 0.80 & 0.05 & $0.72-0.90$ \\
\hline & Monogamous, third widowhood & 0.95 & 0.10 & $0.78-1.16$ & 0.96 & 0.10 & $0.78-1.17$ \\
\hline & Polygamous, two wives, both alive & 0.85 & 0.03 & $0.79-0.92$ & 0.85 & 0.04 & $0.78-0.92$ \\
\hline & Polygamous, two wives, one dead & 0.98 & 0.04 & $0.90-1.07$ & 0.98 & 0.05 & $0.89-1.07$ \\
\hline & Polygamous, two wives, both dead & 1.20 & 0.09 & $1.04-1.38$ & 1.19 & 0.09 & $1.03-1.38$ \\
\hline & Polygamous, three wives, all alive & 0.92 & 0.08 & $0.78-1.09$ & 0.91 & 0.08 & $0.76-1.09$ \\
\hline & Polygamous, three wives, one dead & 1.08 & 0.07 & $0.94-1.23$ & 1.07 & 0.08 & $0.93-1.23$ \\
\hline & Polygamous, three wives, two dead & 1.04 & 0.09 & $0.88-1.22$ & 1.02 & 0.09 & $0.86-1.21$ \\
\hline & Polygamous, three wives, all dead & 1.52 & 0.29 & $1.04-2.23$ & 1.54 & 0.30 & $1.05-2.27$ \\
\hline & Polygamous, four plus wives, all alive & 0.80 & 0.15 & $0.56-1.17$ & 0.78 & 0.15 & $0.54-1.14$ \\
\hline & Polygamous, four plus wives, one dead & 0.81 & 0.12 & $0.60-1.09$ & 0.80 & 0.12 & $0.59-1.08$ \\
\hline & Polygamous, four plus wives, two dead & 0.93 & 0.15 & $0.67-1.29$ & 0.93 & 0.16 & $0.66-1.29$ \\
\hline & Polygamous, four plus wives, three dead & 0.80 & 0.16 & $0.55-1.18$ & 0.81 & 0.16 & $0.55-1.19$ \\
\hline & Polygamous, four plus wives, all dead & 1.31 & 0.41 & $0.70-2.43$ & 1.41 & 0.45 & $0.76-2.63$ \\
\hline \multirow[t]{11}{*}{ Birth cohort } & $<1800$ & 1.03 & 0.04 & $0.95-1.11$ & 0.98 & 0.04 & $0.90-1.06$ \\
\hline & 1800-1809 & 1.13 & 0.04 & $1.06-1.22$ & 1.07 & 0.04 & $1.00-1.16$ \\
\hline & $1810-1819$ & 1.08 & 0.03 & $1.02-1.14$ & 1.05 & 0.03 & $0.99-1.11$ \\
\hline & $1820-1829$ & 1.07 & 0.02 & $1.02-1.11$ & 1.08 & 0.02 & $1.04-1.13$ \\
\hline & $1830-1839$ & 1.04 & 0.02 & $1.00-1.07$ & 1.10 & 0.02 & $1.06-1.14$ \\
\hline & 1840-1849 & 1.06 & 0.02 & $1.03-1.09$ & 1.13 & 0.02 & $1.09-1.17$ \\
\hline & $1850-1859$ & 1.04 & 0.01 & $1.01-1.06$ & 1.07 & 0.01 & $1.05-1.10$ \\
\hline & $1860-1869$ & 1.02 & 0.01 & $1.00-1.04$ & 1.03 & 0.01 & $1.01-1.06$ \\
\hline & $1870-1879$ & 1.00 & & & 1.06 & 0.01 & $1.03-1.08$ \\
\hline & $1880-1889$ & 1.06 & 0.01 & $1.04-1.08$ & 1.00 & & \\
\hline & $1890-1900$ & 0.87 & 0.01 & $0.85-0.88$ & 0.86 & 0.01 & $0.85-0.88$ \\
\hline Membrership & Non-member & 1.00 & & & 1.00 & & \\
\hline \multirow[t]{2}{*}{ of Church of LDS } & Inactive & 1.01 & 0.01 & $0.98-1.03$ & 1.00 & 0.01 & $0.98-1.03$ \\
\hline & Active & 0.81 & 0.01 & $0.80-0.82$ & 0.83 & 0.01 & $0.82-0.85$ \\
\hline \multirow[t]{2}{*}{ Farmer } & No & & & & 1.00 & & \\
\hline & Yes & & & & 0.90 & 0.01 & $0.88-0.93$ \\
\hline Nam-Powers & 1 & & & & 1.15 & 0.05 & $1.06-1.24$ \\
\hline \multirow[t]{10}{*}{ occupational score } & 2 & & & & 0.83 & 0.02 & $0.79-0.88$ \\
\hline & 3 & & & & 1.09 & 0.02 & $1.05-1.13$ \\
\hline & 4 & & & & 0.87 & 0.02 & $0.83-0.91$ \\
\hline & 5 & & & & 0.89 & 0.02 & $0.86-0.92$ \\
\hline & 6 & & & & 1.00 & & \\
\hline & 7 & & & & 0.85 & 0.02 & $0.82-0.88$ \\
\hline & 8 & & & & 0.81 & 0.01 & $0.78-0.84$ \\
\hline & 9 & & & & 0.78 & 0.02 & $0.75-0.81$ \\
\hline & 10 & & & & 0.77 & 0.02 & $0.73-0.81$ \\
\hline & Missing & & & & 1.04 & 0.01 & $1.01-1.07$ \\
\hline \multirow[t]{14}{*}{ Biological parity } & 0 & & & & 1.00 & & \\
\hline & 1 & & & & 0.95 & 0.02 & $0.92-0.98$ \\
\hline & 2 & & & & 0.95 & 0.02 & $0.93-0.98$ \\
\hline & 3 & & & & 0.93 & 0.01 & $0.90-0.96$ \\
\hline & 4 & & & & 0.92 & 0.01 & $0.89-0.95$ \\
\hline & 5 & & & & 0.91 & 0.01 & $0.88-0.94$ \\
\hline & 6 & & & & 0.91 & 0.01 & $0.88-0.94$ \\
\hline & 7 & & & & 0.89 & 0.01 & $0.86-0.92$ \\
\hline & 8 & & & & 0.91 & 0.02 & $0.88-0.94$ \\
\hline & 9 & & & & 0.91 & 0.02 & $0.88-0.95$ \\
\hline & 10 & & & & 0.93 & 0.02 & $0.89-0.96$ \\
\hline & $11-14$ & & & & 0.92 & 0.02 & $0.89-0.95$ \\
\hline & $15-19$ & & & & 0.91 & 0.03 & $0.86-0.97$ \\
\hline & $20+$ & & & & 0.94 & 0.04 & $0.86-1.04$ \\
\hline \multirow{2}{*}{ Born outside of Utah } & No & & & & 1.00 & & \\
\hline & Yes & & & & 0.92 & 0.01 & $0.91-0.93$ \\
\hline \multirow{2}{*}{\multicolumn{2}{|c|}{$\begin{array}{l}\mathrm{N} \\
\text { Deaths }\end{array}$}} & \multicolumn{3}{|c|}{106,898} & \multicolumn{3}{|c|}{106,898} \\
\hline & & \multicolumn{3}{|c|}{102,998} & & 102 & \\
\hline
\end{tabular}

